\title{
IRG1 controls immunometabolic host response and restricts intracellular Mycobacterium tuberculosis infection
}

Eik Hoffmann ${ }^{1,}$, Arnaud Machelart ${ }^{1}$, Imène Belhaouane ${ }^{1}$, Nathalie Deboosere ${ }^{1}$, Anne-Marie Pauwels ${ }^{2,3}$, Jean-Paul Saint-André4, Ok-Ryul Song ${ }^{1}$, Samuel Jouny ${ }^{1}$, Anaïs Poncet ${ }^{1}$, Sabrina Marion ${ }^{1}$, Rudi Beyaert²,3, Laleh Majlessi ${ }^{5,6}$, Priscille Brodin ${ }^{1, *}$

1 Univ. Lille, CNRS, INSERM, CHU Lille, Institut Pasteur de Lille, U1019 - UMR 8204 - CIIL - Center for Infection and Immunity of Lille, Lille, France

2 Unit of Molecular Signal Transduction in Inflammation, VIB-UGent Center for Inflammation Research, Ghent, Belgium

${ }^{3}$ Department of Biomedical Molecular Biology, Ghent University, Ghent, Belgium

${ }^{4}$ University Hospital Center of Angers, Angers, France

${ }^{5}$ Institut Pasteur, Unit for Integrated Mycobacterial Pathogenomics, CNRS UMR 3525, Paris, France

${ }^{6}$ Theravectys Joint Lab, Institut Pasteur Biotop, Paris, France

${ }^{*}$ To whom correspondence should be addressed:

Eik Hoffmann; E-mail: eik.hoffmann@ibl.cnrs.fr; Tel.: +33 320871035

Priscille Brodin; E-mail: priscille.brodin@inserm.fr; Tel.: +33 320871184

Short title: Immunometabolic host response to tuberculosis

Keywords: dendritic cell; host-pathogen interactions, lipid droplets; macrophage, metabolic reprogramming, tuberculosis 


\section{Abstract}

Mycobacterium tuberculosis (Mtb), the pathogen causing human tuberculosis, has evolved multiple strategies to successfully prevent clearance by immune cells and to establish dissemination and long-term survival in the host. The modulation of host immunity to maximize pathogen elimination while minimizing inflammation-mediated tissue damage may provide another tool to fight drug-resistant $M$ tb strains. Metabolic reprogramming of immune cell populations can dramatically influence the outcome of immune responses and modulate antimicrobial properties of infected host cells, nicely demonstrating that metabolites are tightly linked to immune cell effector functions. One important endogenous metabolite of the Krebs cycle is itaconate, which has potent bactericidal activity by inhibiting isocitrate lyase and the glyoxylate shunt within prokaryotes including mycobacteria. Recent findings show that itaconate and the catalytic enzyme responsible for its generation in mammalian cells, i.e. IRG1 (immune-responsive gene 1), also modify inflammatory signaling of infected cells enhancing host defense pathways.

Here, we demonstrate that IRG1 is recruited to Mtb-containing phagosomes and that it influences the host response controlling Mtb infection. While IRG1 deficiency does not affect uptake of Mtb by macrophages and dendritic cells (DCs) in vitro, it increases the intracellular replication of Mtb. Concomitantly, in comparison to wild type cells, IRG1-deficient macrophages and DCs have increased levels of lipid droplets, a correlate of inflammation. These intracellular organelles store triacylglycerol and phospholipids that are hijacked by Mtb as reservoir of host nutrients. Exposure of IRG1-deficient mice to M. bovis BCG via the intranasal route induced neither lethality nor severe lung immunopathology, while IRG1-deficient mice were highly susceptible to Mtb infection resulting in animal death three weeks post-infection linked to exacerbated inflammation and high mycobacterial burden. The lungs of infected IRG1-deficient mice displayed large areas of necrotizing granulomatous inflammation and neutrophil infiltration, accompanied by reduced levels of B and T lymphocytes and increased levels of alveolar and interstitial macrophage populations, compared to their wild type counterparts. Therefore, our findings demonstrate that IRG1 is a major player in controlling the acute phase of $M t b$ infection with a specific effect on pathogenic mycobacteria. 


\section{Introduction}

Protective immunity of host cells during their infection by bacterial pathogens includes a broad variety of pathways and spatially regulated molecular players. Although the interplay between mechanisms of antimicrobial resistance and adapted tolerance of inflammatory responses is able to control infection, e.g. in the lung (Meunier et al. 2017), several pathogens have evolved strategies to resist host defense and to persist for long time periods (Escoll \& Buchrieser 2019). Mycobacterium tuberculosis (Mtb), responsible for tuberculosis (TB) in humans, is transmitted by aerosol droplets followed by engulfment by alveolar macrophages and dendritic cells (DCs) in the lung. Mtb is able to evade different innate antimicrobial mechanisms of host cells and replicates intracellularly (Philips \& Ernst 2012). In addition, host adaptive immune responses are activated and slow down mycobacterial growth, but Mtb infection can also lead to chronic forms of TB. Therefore, TB remains the most common infectious cause of death worldwide, responsible for an estimated 1.3 million deaths each year, together with a dramatic increase in the emergence of multidrug- and extensively drug-resistant Mtb strains (WHO, Global TB Report 2018). While any organ in the body can be affected by Mtb infection, new infectious cycles are induced by transmission of pulmonary forms of the disease (Cadena \& Fortune 2017). Bacillus Calmette-Guérin (BCG) is the only available vaccine against TB, but is not sufficiently successful in preventing active TB (Kaufmann et al. 2018). Currently, several novel vaccine candidates are at different stages of clinical trial development in addition to adjuvant strategies and mechanisms to boost current TB vaccines and antibiotics (Andersen \& Scriba 2019). They are at early stages of development and thus require improved understanding of the mechanisms that mediate subversion of host immunity and would help to control the disease.

In recent years, novel host-directed therapies (HDTs) against TB are in development that support elimination of mycobacteria by the host while reducing tissue damage induced by the infection, which have an impact on TB morbidity and mortality (Machelart et al. 2017). Advances in the understanding of immunometabolism shed light on the intimate link between metabolic states of immune cells and their specific functions during infection and inflammation (Escoll \& Buchrieser 2019) and are increasingly applied to improve HDTs against different infectious diseases, including TB (Russell et al. 2019; Shi et al. 2019). The Mtb-infected host cell microenvironment is characterized by dysregulated immunoregulation pathways, for example, Th1/Th17 versus Th2 balance, regulatory $T$ and suppressive myeloid cell populations and a 
shift from M1-like to M2-like polarized macrophages (Jayashankar \& Hafner 2016). Recent studies have shown that changes in specific host metabolites can be mapped to cellular effector mechanisms and drive different inflammatory phenotypes of immune cells (O’Neill \& Pearce 2016). Itaconate, a host metabolite that is only produced by different immune cell populations upon pro-inflammatory stimuli, such as LPS and type I and II interferons, received increasing attention in recent years (O'Neill \& Artyomov 2019). Itaconate is generated from cis-aconitate in the tricarboxylic acid (TCA) cycle by the catalytic enzyme immuneresponsive gene 1 (IRG1), also known as aconitate decarboxylase 1 (ACOD1) (Michelucci et al. 2013). It has previously been shown that itaconate has antimicrobial activity by inhibiting isocitrate lyase (McKinney et al. 2000), an enzyme of the glyoxylate shunt, which is present in most prokaryotes but absent in mammals. Persistence of Mtb infection requires isocitrate lyase (McKinney et al. 2000), and recent findings showed that itaconate also plays an immunoregulatory role in macrophages, e.g. by inhibiting succinate dehydrogenase (Lampropoulou et al. 2016), regulating Nrf2 activity (Mills et al. 2018) and modulating electrophilic stress responses (Bambouskova et al. 2018). In turn, those activities are able to influence hostpathogen interactions, as it was shown in macrophages during Legionella pneumophila infection (Naujoks et al. 2016; Price et al. 2019). More recently, Nair et al. showed that IRG1-deficient mice are highly susceptible to Mtb infection, while no aberrant phenotypes were found during influenza A virus or Listeria monocytogenes infection (Nair et al. 2018). Their findings suggest that IRG1 expression in myeloid cells shape immunometabolic host responses by regulating neutrophil-dependent inflammation during $M t b$ infection of the lung. However, the underlying intracellular activities of Mtb-infected immune cells and their contribution to the observed phenotype remained unknown.

Here, we show that IRG1 is induced upon Mtb infection and is directly recruited to Mtb-containing phagosomes. IRG1-deficient phagocytes showed elevated Mtb infection rate and increased Mtb growth in comparison to WT cells resulting in increased mycobacterial numbers in vitro after 4 days post-infection. These observations are accompanied by findings that demonstrate that IRG1-deficient macrophages and DCs have increased levels of lipid droplets, which are reservoirs of host nutrients for $M t b$. Similar to the previous report using aerosol infection with the Mtb Erdman strain (Nair et al. 2019), we found that intranasal inoculation of IRG1-deficient mice by Mtb H37Rv induced severe lung immunopathology and mortality of infected mice. Exacerbated inflammation and high mycobacterial burden in the lungs of Mtb-infected, IRG1- 
deficient mice was accompanied by large areas of necrotizing granuloma formation, neutrophil infiltration and a pronounced reduction in the number of B and T lymphocytes. Importantly, exposure of IRG1-deficient mice to $M$. bovis BCG via the intranasal route induced neither lethality nor severe lung immunopathology demonstrating that the phenotype observed in Mtb-infected mice is linked to pathogenic virulence. Therefore, our findings demonstrate that IRG1 is a major player in controlling the acute phase of Mtb infection.

\section{Results}

To evaluate the possible contribution of IRG1 during Mtb infection in vitro, we first established the Irg1 gene expression profile of bone marrow-derived macrophages (BMDMs) infected by the virulent Mtb H37Rv strain using quantitative RT-PCR. While Irg1 was not expressed in resting, non-infected BMDMs, stimulation of cells with LPS (100 ng/ml) and IFN $\gamma(20 \mathrm{ng} / \mathrm{ml})$ for $24 \mathrm{~h}$ induced $/ \mathrm{rg} 1$ expression considerably

(Figure 1A), in accordance with previous observations (Lampropoulou et al. 2016). Infection by Mtb (MOI = 1) also rapidly induced $\operatorname{lrg} 1$ expression in BMDMs and showed increased levels between $2 \mathrm{~h}$ and $48 \mathrm{~h}$ post-infection (hpi), with almost undetectable levels at $96 \mathrm{hpi}$, comparable to non-infected cells (Figure 1A). Full absence of Irg1 signal in BMDMs obtained from IRG1-deficient mice (IRG1 ${ }^{-/}$) showed the high specificity of the RT-PCR approach (Figure 1A). In accordance, the IRG1 protein was upregulated, as detected by western blotting, in lysates of LPS-stimulated or Mtb-infected BMDMs (Figure 1B). LPS stimulation induced the expression of IRG1 at $6 \mathrm{~h}$ and was found at higher levels at $24 \mathrm{~h}$ and $48 \mathrm{~h}$ after LPS stimulation. Infection of BMDM by Mtb induced a comparable profile of IRG1 expression, detectable between $6 \mathrm{~h}$ and $48 \mathrm{~h}$ post-infection. In both cases, IRG1 was absent in cell lysates at $96 \mathrm{~h}$ (Figure 1B), in accordance with the results generated by quantitative RT-PCR. In addition to BMDMs, LPS stimulation also induced IRG1 expression in bone marrow-derived dendritic cells (BMDCs), as detected in total cell lysates (TCL) from resting versus LPS-stimulated BMDCs (Figure 1C).

Intracellular pathogens, such as Mtb, that enter immune cells by phagocytosis, are located in phagosomes, which further interact with endosomal compartments during phagosome maturation. In a previous study, using a well-established phagocytosis model system of antigen-coupled beads (Hoffmann 
et al. 2012), we identified by quantitative mass spectrometry the specific recruitment of IRG1 to phagosomes of LPS-stimulated BMDCs (Pauwels et al. 2019). We confirmed this observation by western blotting analyzing purified latex bead-containing phagosomes (LBP). We found IRG1 present in LBP lysates of LPS-stimulated BMDCs, while it was absent in phagosomal lysates of resting BMDCs (Figure 1C). In contrast, lysosome-associated membrane protein 1 (LAMP-1), a membrane glycoprotein originated from late endosomes and lysosomes, was recruited to LBPs of both, resting and LPS-stimulated BMDCs (Figure 1C). In addition, previous work on macrophage infection by Legionella pneumophila showed that IRG1 could also be recruited to Legionella-containing phagosomes (Naujoks et al. 2016). Therefore, we examined a possible association of IRG1 with Mtb-containing phagosomes. Mtb-infected BMDMs were fixed 24 hpi and labeled for IRG1, F-actin and nuclei for analysis by confocal microscopy (Figure 1D). IRG1 was found recruited to $M$ tb-containing phagosomes, as several IRG1 signals (green) co-localized with Mtb signals (red) (insets in Figure 1D). In other parts of the cell, IRG1 remained located outside of phagosomes restricted to other cell organelles, such as mitochondria, as demonstrated previously for pro-inflammatory conditions (Tallam et al. 2016). These findings demonstrated that IRG1 is induced upon Mtb infection, followed by its recruitment to Mtb-containing phagosomes, suggesting a role of IRG1 in the intracellular host defense against mycobacteria.

To further study the characteristics of IRG1 during Mtb infection, we infected BMDMs and BMDCs derived from WT mice or IRG1\%- mice with a GFP-expressing Mtb H37Rv strain and followed colonization of host cells and Mtb replication during $96 \mathrm{~h}$. Cells were grown in 384-well plates and their nuclei were labeled to enable analysis by an automated confocal microscopy approach using in-house multiparametric imaging that allowed acquisition and examination of hundreds of images generating robust and reproducible data sets (Song et al. 2017). Algorithms were applied to input images, which resulted in segmentation of the different fluorescent signals allowing nuclei detection, cell and bacteria selection and further downstream analysis to determine infection rate and number of bacteria per cell (Figure 2A). First, we observed that the efficacy of Mtb uptake by WT and IRG1/- phagocytes were comparable, as determined by the percentages of Mtb-infected BMDMs and BMDCs at 2 hpi (Figure 2B). We then compared the Mtb intracellular area per infected cell, which directly correlates with the number of Mtb per cell (Queval et al. 2016), which showed no differences between WT and IRG1/- BMDMs and BMDCs at 2 hpi (Figure 2C). In 
contrast, at 96 hpi the percentages of Mtb-infected BMDMs and BMDCs were largely increased in IRG ${ }^{-/}$ BMDMs and BMDCs (Figure 2B), showing that IRG1 deficiency favors survival and/or intracellular growth of Mtb. This was further supported by the fact that at $96 \mathrm{hpi} \mathrm{IRG1-deficient} \mathrm{BMDMs} \mathrm{and} \mathrm{BMDCs} \mathrm{also} \mathrm{had}$ significantly higher Mtb numbers per cell compared to WT phagocytes (Figure 2C). These findings indicate that the expression of IRG1, induced by Mtb infection, and the presence of IRG1 during the course of infection enable host cells to restrict excessive growth and replication of Mtb.

A key regulator of host immunity to intracellular bacterial pathogens, including Mtb (Braverman et al. 2016), is hypoxia inducible factor $1 \alpha$ (HIF1 $\alpha$ ), which controls inflammatory and antimicrobial responses during infection (Knight \& Stanley 2019). HIF1 $\alpha$ protein levels are regulated by oxygen and in response to fluctuating metabolite levels (Koivunen et al. 2007), which activate and stabilize HIF1 $\alpha$ leading to the expression of inflammatory cytokines, such as IL-1 (Tannahill et al. 2013). Based on these facts, we investigated a possible impact of IRG1 activity and itaconate production on the regulation and activity of HIF1 $\alpha$ and IL-1 $1 \beta$, which might influence the intracellular replication of Mtb. We quantified the expression of Hif1a and I/1b by quantitative RT-PCR in WT and IRG1/- BMDMs during Mtb infection or LPS and IFN $\gamma$ stimulation. While in non-infected cells we observed reduced Hif1a transcription in IRG1\% BMDMs compared to WT cells, such difference was not observed during the course of Mtb infection or LPS and IFN $\gamma$ stimulation (Figure S1A). At an extended Mtb infection time point, i.e. 48 h, largely enhanced Hif1a transcription was detected in both, WT and IRG1/- BMDMs. Transcription of $/ / 1 \mathrm{~b}$ was at the detection limit in non-infected cells (Figure S1B). After $48 \mathrm{~h}$, LPS and IFN $\gamma$ stimulation induced substantial $/ / 1 b$ transcription in WT BMDMs. Although IRG1/- BMDMs also upregulated this cytokine, they were less prone to express it compared to WT cells. In the case of Mtb infection, even though at 48 hpi comparable transcription of $/ / 1 \mathrm{~b}$ was detected in WT and IRG1/- BMDMs, at 24 hpi such transcription was only detectable in WT cells, suggesting a delayed inflammatory response to Mtb infection in this cell type. In parallel, we quantified in culture supernatants the secretion of pro-inflammatory cytokines by WT and IRG11- BMDMs at different time points post-infection. Mtb infection of BMDMs induced secretion of IL-1 $\alpha$, IL-1 $\beta$, IL-6, MCP-1 (CCL2) and TNF compared to non-infected control cells (Figure S1C). Levels of IL-1 $\alpha$, IL-1 $\beta$ and IL-6 increased during the course of infection, in particular for WT cells, while levels of MCP-1 and TNF were lower at later infection time points (48 hpi and $96 \mathrm{hpi}$ ) compared to an earlier time point (24 hpi). 
Although we observed a net tendency of impaired secretion of IL-1 $\alpha$ and IL-1 $\beta$ by IRG 1 - BMDMs, the differences between WT and IRG1-- cells were not statistically significant. Finally, we also applied an imaging approach on BMDMs grown and infected in 384-well plates, using automated confocal microscopy and multiparametric image analysis to distinguish between cytosolic and nuclear HIF1 $\alpha$ activities (Figure S1D). Mean fluorescence intensities of HIF1 $\alpha$ were higher in the nucleus than cytosolic levels, but we did not observe differences between WT and IRG1/- BMDMs (Figure S1E). Mtb infection increased abundance of nuclear HIF1 $\alpha$, again similarly in WT and IRG1/- cells. Therefore, it is seemingly that the increased Mtb persistence/replication in IRG1/- phagocytes in vitro is not a direct consequence of altered inflammatory and/or antimicrobial responses modulated by HIF1 $\alpha$ activation.

Metabolite generation and host cell homeostasis are intimately connected and can affect outcome of immune responses. Previous observations have shown that $M t b$ persistence/replication relies on the availability of host nutrients that the bacteria exploit to build their replicative niche in phagocytes. In recent years, lipid droplets (LDs) were recognized as dynamic players of lipid metabolism and important regulators of immune cell function (den Brok et al. 2018). During infection, the key carbon source for intracellular Mtb consists of host lipids that are mainly stored in LDs (Peyron et al. 2008), and which are also responsible of the foamy phenotype of macrophages inside tuberculosis granuloma (Russell et al. 2009). Furthermore, the ESX-1 secretion system of Mtb was shown to interfere with host homeostasis and lipid metabolism favoring actively the formation of LDs in infected host cells (Singh et al. 2012). Therefore, we investigated the impact of IRG1 deficiency on the formation of LDs and their availability in host cells during Mtb infection in vitro. We used a specific dye to label neutral LDs in BMDMs and BMDCs at $96 \mathrm{hpi}$, i.e. the time point where differences in Mtb replication rate were obvious (Figure 2B-C). We again applied automated confocal microscopy and multiparametric image analysis to detect and quantify LDs in both cell types (Figure 3A). While non-infected BMDMs and BMDCs exhibited very low percentages of LD-positive cells (Figure 3B) or low LD numbers per cell (Figure 3C), Mtb infection increased the rate of LD-positive cells and LD numbers per cell. The percentage of LD-positive cells was further increased in the IRG1/- BMDMs and BMDCs compared to WT cells (Figure 3B), and those cells showed significantly more LDs per cell (Figure 3C). This was further supported, when samples were evaluated manually by blinded analysis to verify the applied script of automated image analysis. While infected WT BMDMs displayed $2.7 \pm 0.3$ LDs 
per cell, infected IRG1 ${ }^{-/}$BMDMs had 10.4 \pm 2.3 LDs per cell (Figure 3D). These results demonstrate clearly that the presence of IRG1 function, is concomitant with the reduction of LDs in macrophages and DCs during Mtb infection.

Next, we explored the physiological relevance of IRG1 deficiency during Mtb infection in vivo using an established infection model in C57BL/6 mice. A previous study demonstrated that, compared to WT mice, their IRG1 ${ }^{-/}$counterparts were more susceptible to aerosol infection with the Mtb Erdman strain (Nair et al. 2018). Here, we comparatively evaluated, in WT and IRG $1^{-/}$mice, the impact of the intranasal inoculation of the high dose of $1 \times 10^{5}$ colony-forming units (CFU) per mouse of the virulent Mtb H37Rv strain or the attenuated M. bovis BCG Pasteur vaccinal strain 1173P2 (Figure 4A). Body weight, mycobacterial burden and survival were thus monitored during the course of infection for at least 77 days post-infection (dpi). During the first two weeks post-infection, the body weight of WT and IRG $1^{-/-}$mice, either infected with Mtb or BCG, did not show any difference. From 14 dpi onwards, IRG1/- mice exposed to Mtb started to lose approximately one gram of body weight daily, while WT mice exposed to Mtb or BCG, as well as IRG1/- mice exposed to BCG were not affected (Figure 4B). In contrast to the WT mice exposed to $M t b$ or $B C G$ and the IRG1- mice exposed to BCG, which even until $77 \mathrm{dpi}$ did not display loss in body weight nor morbidity or mortality, all Mtb-exposed IRG1-- mice reached moribund conditions and died between 3 and 4 weeks post-infection (Figure 4C), similar to IRG1/- mice infected by Mtb Erdman (Nair et al. 2018), and confirming the substantial susceptibility of mice to Mtb infection in the absence of functional IRG1.

At $21 \mathrm{dpi}$, the lungs of Mtb-infected IRG1/- mice were enlarged and displayed macroscopic pathological features with areas of necrotizing lesions (Figure 4D). Histological examination of the lungs using hematoxylin phloxine saffron staining showed massive granulomatous inflammation in Mtb-exposed IRG1\% mice compared to their WT counterparts (Figure 4E). Ziehl-Neelsen staining of mycobacteria applied to the histological lung sections detected substantial amounts of invading Mtb in the lung parenchyma of IRG1 ${ }^{-/}$mice (Figure 4F, inset 2), while lungs of WT mice contained much lower numbers of $M$ tb (Figure 4F, inset 1). Determination of mycobacterial loads at different time points post-infection demonstrated that while Mtb loads in the lung were comparable at the day of intranasal inoculation and during the first two weeks of the infection (7 dpi, $14 \mathrm{dpi}$ ), 20 -fold more CFU were detected in the lungs of 
IRG1- mice (CFU mean: $58.0 \times 10^{6} \pm 2.3 \times 10^{6}$ ) compared to WT mice (CFU mean: $2.8 \times 10^{6} \pm 0.9 \times 10^{6}$ ) at 21 dpi (Figure 5A). In addition, examination of tracheobronchial lymph node, spleen and liver showed Mtb dissemination from $7 \mathrm{dpi}$ and/or 14 dpi onwards. In BCG-exposed WT and IRG1/- mice, similar mycobacterial lung burdens were detected at $0 \mathrm{dpi}$ and $7 \mathrm{dpi}$ (Figure 5B). At $14 \mathrm{dpi}$, BCG burden in the lungs of IRG1 $1^{--}$mice was already higher than in WT controls. At the late time point of 86 dpi, only few amounts of residual BCG were still detectable in the lungs of WT mice, while IRG1\% mice contained substantial amounts of BCG (Figure 6A). In accordance, BCG was still detectable even at 86 dpi at relatively high amounts in the trancheobronchial lymph nodes and livers of IRG1/- mice. Altogether, these results indicate a major contribution of IRG1, and its catalytic product itaconate, in the antimicrobial host response not only at the mucosal site of infection but also systemically. Our observations in vivo clearly indicate that IRG1- mice are highly susceptible to virulent $M t b$ developing a severe phenotype leading to the death of all animals within 3-4 weeks. Infection of IRG1-- mice with an attenuated mycobacterial strain (M. bovis BCG) leads to lower pathogenicity, but these mice still show a higher susceptibility compared to infected WT mice, and BCG mycobacteria are able to persist at high levels in these mice long after the exposure.

Finally, we performed immune cell characterization in WT and IRG $1^{-/}$mice during the entire Mtb infection period until $21 \mathrm{dpi}$ by determining the total cell numbers of macrophages, eosinophils, DCs, neutrophils, CD4+ $\mathrm{T}$ cells, CD8 ${ }^{+} \mathrm{T}$ cells and $\mathrm{B}$ cells in lungs and spleen. Until $14 \mathrm{dpi}$, all lung and splenic cell populations were comparable between WT and IRG1/- mice and did not show remarkable differences (Figure 6A, Figure S2). In contrast, the time period between $14 \mathrm{dpi}$ and $21 \mathrm{dpi}$ led to a dramatic increase in pulmonary macrophages (both alveolar and interstitial ones) as well as neutrophils in the lungs of IRG11- mice, while levels of CD4+ $T$ cells, $C D 8^{+} T$ cells and B cells were significantly decreased compared to WT mice (Figure 6A). In the spleen, DCs and neutrophils were significantly increased in IRG1/- mice at $21 \mathrm{dpi}$, while $\mathrm{CD}^{+} \mathrm{T}$ cells and B cells exhibited a reduction compared to WT cells (Figure S2). These findings demonstrate that macrophages (in the lung), DCs (in the spleen) and neutrophils (in both organs) are the main cell populations that are responsible for the increased progression of Mtb infection in IRG $1^{-/}$mice. This is underlined by the fact that neutrophils in the lungs of IRG1- mice displayed a dramatically higher mycobacterial burden compared to lungs of their WT counterparts, when they were labeled in situ (Figure 6B). In line with this, the observed reduction in T cell and B cell levels in both, lung and spleen, of IRG $1^{-/}$ 
mice might suggest impaired adaptive immunity in those animals compared to Mtb-infected WT mice, which could be beneficial to Mtb progression and immunopathology observed in IRG $1^{-1-}$ animals. Altogether, our findings clearly indicate an important role of IRG1 in the immunometabolic host response to Mtb infection.

\section{Discussion}

The mammalian catalytic enzyme IRG1 and its generated metabolite itaconate are only induced during infection and/or inflammation (Basler et al. 2006) and were previously described for their antimicrobial activities (McKinney et al. 2000, Michelucci et al. 2013, Naujoks et al. 2016, Nair et al. 2018, Price et al. 2019). In this study, we addressed the role of IRG1 in immunometabolic host responses during Mtb infection and were able to demonstrate that IRG1 is essential for the outcome of immunopathology, both in vitro and in vivo. Our findings showed that expression of IRG1 is induced during Mtb infection and controls the formation of LDs to restrict intracellular pathogen growth, which we have summarized in Figure 7. In the lungs of both, WT and IRG1-- mice, alveolar macrophages internalize Mtb during infection, which induces Irg1 expression and leads to the recruitment of the IRG1 protein to Mtb-containing vacuoles in WT conditions (inset in Figure 7). IRG1 restricts the generation of LDs in infected WT cells leading to a limited availability of host nutrients for Mtb, which confines intracellular replication and growth of the pathogen. In contrast, absence of IRG1 during Mtb infection leads to uncontrolled formation of LDs and exacerbated pathogen growth in host cells. In addition, increased inflammation in the lung of IRG $1^{-/}$mice and elevated infiltration of neutrophils further support systemic dissemination of $M t b$, e.g. by neutrophils internalizing dying phagocytes that are massively invaded by $M t b$. The observed reduction of $T$ and $B$ lymphocytes in lungs and spleens of IRG1/- mice possibly affects adaptive immune responses to Mtb infection and further attenuates immunity and host response in those animals.

A previous study (Nair et al. 2018) investigating the impact of IRG1 on Mtb infection using the Erdman strain by aerosol inoculation showed similar susceptibility and immunopathological features of IRG1 ${ }^{-1-}$ mice with increased mycobacterial loads in lungs and spleen at $21 \mathrm{dpi}$. Importantly, we show here on the subcellular level, by applying automated confocal microscopy to macrophages and DCs, that this observation is a consequence of the uncontrolled generation of lipid droplets and increased mycobacterial 
replication in IRG1/- phagocytes. Furthermore, we show here that the higher susceptibility of IRG1-deficient mice is not only specific to mycobacteria, but is also directly linked to the virulence of $M t b$. Nair et al. showed that infection of mice by Listeria monocytogenes and influenza A virus did not result in altered susceptibility of IRG $1^{-/}$animals. In our study, we provide evidence that IRG $1^{-/-}$mice are only highly susceptible to virulent Mtb but not to attenuated mycobacterial species, such as the vaccinal strain $M$. bovis BCG. Nonetheless, BCG-infected IRG1\% mice displayed differences compared to BCG-infected WT mice, because mycobacteria were able to persist at higher levels in absence of IRG1 expression long after the initial exposure. Therefore, future work is needed to identify the factors that contribute to the link between pathogen virulence and susceptibility of IRG1-deficient animals.

For the first time, we could show in our study that IRG1 is recruited to Mtb-containing vacuoles, as it has been demonstrated previously for Legionella pneumophila-containing vacuoles (Naujoks et al. 2016). In both cases, pathogen growth is reduced indicating that presence of IRG1 in those vacuoles might lead to the local production of itaconate and generating an antimicrobial gradient in these cell organelles. Another IFN-inducible protein has been identified in the past that localized to Mtb-containing vacuoles. The intracellular localization of Interferon-induced transmembrane protein 3 (IFITM3) overlapped with Mtb localized in late phagosomes, and IFITM3 overexpression was able to inhibit Mtb growth in human monocytes (Ranjbar et al. 2015). Intriguingly, recent work investigating Pseudomonas aeruginosa infection showed that dysfunction in cystic fibrosis transmembrane conductance regulator (CFTR) stimulated mitochondrial activity and led to an anti-inflammatory host response controlled by IRG1 and itaconate leading to an inefficient clearance of this pathogen (Riquelme et al. 2019). A bacterial killing capacity of CFTR has been described previously controlling phagosomal $\mathrm{pH}$ and phagolysosomal acidification (Di et al. 2006) and was shown to protect against Mycobacterium abscessus infection (Bernut et al. 2019). The block of phagosomal acidification and hydrolase activity induced by Mtb also requires the activity of ion channels (Sturgill-Koszycki et al. 1994; Wong et al. 2011; Queval et al. 2017; Buter et al. 2019). Therefore, a likely scenario is that $M t b$ virulence factors, such as phoPR, interfere with chloride ion levels in host cells (Tan et al. 2013; Baker et al. 2019) to interfere with the antimicrobial activity of IRG, which needs to be addressed in future studies. 
In our settings, IRG1 deficiency led to the increased formation of LDs during Mtb infection in macrophages and DCs. A previous study showed that LD formation is resulting from immune activation of macrophages as part of their host defense mechanism against Mtb infection and is not directly induced by the pathogen itself (Knight et al. 2018). The authors showed that this HIF1 $\alpha$-dependent signaling pathway, and its target gene Hig2, were required for the majority of LD formation in the lungs of Mtb-infected mice. Our findings, on the other hand, suggest that increased LD generation in IRG1/- phagocytes favors Mtb replication and growth indicating a dependence of this pathogen on host lipids stored in host LDs. Although our results excluded the direct participation of HIF1 $\alpha$ in this process, since HIF1 $\alpha$ expression and activation were not affected by IRG1 deficiency, future investigations need to rule out the divergent role of host enzymes involved in LD biogenesis, such as DGAT1 and DGAT2, in this process (Bhatt-Wessel et al. 2018). Changes in available host lipids also have direct consequences on the modulation of adaptive immune responses. For example, LD generation was correlated to efficacy and regulation of cross-presentation pathways (Bougnères et al. 2009), which include exogenous antigens derived from Mtb infection. In addition, Mtb virulence factors were shown to interfere with LD formation (Elamin et al. 2011). Our observations that IRG1 deficiency induced a severe reduction in T and B cell compartments in Mtb-infected lungs and spleens, further emphasizes the role of players of adaptive immunity in the progression of $M$ tb immunopathologies and requires further investigation. Overall, we could show in our study that immunometabolic host responses during $M$ tb infection are essential to control infection outcome and immunopathology. IRG1 expression and itaconate production are one of the key nodes that determine efficient host immunity in TB suggesting that their modulation might be used in the future development of HDTs to improve immunometabolic host responses to Mtb infection.

\section{Material and Methods}

Mice. C57BL/6NJ wild type mice and C57BL/6NJ-Acod1em1(IMPC)J/J (IRG1 ${ }^{-/-}$) mice deficient in $\operatorname{lrg} 1$ expression were purchased from The Jackson Laboratory (Bar Harbor, ME, USA). All mice were maintained and breeding was performed in the animal facility of the Pasteur Institute of Lille, France (agreement B59350009). All experimental procedures received ethical approval by the French Committee on Animal 
Experimentation and the Ministry of Education and Research (APAFIS\#10232-2017061411305485 v6, approved on 14/09/2018). All experiments were performed in accordance with relevant guidelines and regulations.

Murine bone marrow-derived macrophages (BMDM) and dendritic cells (BMDC). Murine bone-marrow progenitors were obtained by sampling tibias and femur bones from 7 to 12 week-old C57BL/6NJ wild type and IRG1/- mice. BMDM were obtained by seeding $10^{7}$ bone marrow cells in $75 \mathrm{~cm}^{2}$ flasks in RPMI 1640 Glutamax medium (Gibco) supplemented with 10\% heat-inactivated Fetal Bovine Serum (FBS, Gibco; RPMI-FBS) and 10\% L929 cell supernatant containing Macrophage Colony-Stimulating Factor (M-CSF). After 7 days incubation at $37^{\circ} \mathrm{C}$ in an atmosphere containing $5 \% \mathrm{CO}_{2}$, the $\mathrm{BMDM}$ monolayer was rinsed with D-PBS and cells harvested with Versene (Gibco). BMDC were differentiated as previously described (Alloatti et al., 2015). Briefly, $2 \times 10^{7}$ murine bone marrow progenitors were seeded in $100 \mathrm{ml}$ RPMI-FBS supplemented with 10\% J558-conditioned medium containing Granulocyte-Macrophage ColonyStimulating Factor (GM-CSF) in $500 \mathrm{~cm}^{2}$ square petri dishes (Nunc). Cells were incubated at $37^{\circ} \mathrm{C}$ in $5 \%$ $\mathrm{CO}_{2}$. Fresh medium was added every 3-4 days. On day 10, the supernatant was discarded and adherent cells were harvested using DPBS containing 2 mM EDTA (Sigma-Aldrich). BMDM and BMDC were resuspended into corresponding culture medium to be used for subsequent assays.

Bacteria. Recombinant strains of $M t b \mathrm{H} 37 \mathrm{Rv}$ expressing an enhanced green fluorescent protein (GFP) or a red fluorescent protein DsRed (Christophe et al. 2009) were cultured in Middlebrook 7H9 medium (Difco) supplemented with $10 \%$ oleic acid-albumin-dextrose-catalase (OADC, Difco), $0.2 \%$ glycerol (Euromedex), 0.05\% Tween 80 (Sigma-Aldrich) and $50 \mu \mathrm{g} / \mathrm{ml}$ hygromycin (ThermoFisher Scientific) or $25 \mu \mathrm{g} / \mathrm{ml}$ kanamycin (Sigma-Aldrich) for H37Rv-GFP or H37Rv-DsRed, respectively. Cultures were maintained for 14 days until the exponential phase was reached. Before cell infection, bacilli were washed with Dulbecco's Phosphate Buffered Saline (DPBS, free from $\mathrm{MgCl}_{2}$ and $\mathrm{CaCl}_{2}$, Gibco), resuspended in $10 \mathrm{~mL}$ RPMI-FBS and centrifuged at 1000 RPM for 2 min at room temperature to remove bacterial aggregates. Bacterial titer of the suspension was determined by measuring the optical density $\left(\mathrm{OD}_{600 \mathrm{~nm}}\right)$ and GFP or DsRed fluorescence on a Victor Multilabel Counter (Perkin Elmer). The bacterial suspension was diluted at the required titer in RPMI-FBS. For in vivo studies, Mycobacterium bovis BCG (strain 1173P2) and Mtb H37Rv 
WT strain were grown in Middlebrook 7H9 medium, as described previously (Deboosere et al. 2017, Raze et al. 2018).

Chemicals, Dyes and Antibodies. $100 \mathrm{ng} / \mathrm{ml}$ of ultrapure LPS from E. coli 0111:B4 (Invivogen, France) and $20 \mathrm{ng} / \mathrm{ml}$ of recombinant mouse IFN-gamma (ImmunoTools $\mathrm{GmbH}$, Germany) were used to activate BMDMs. Polyclonal anti-Mycobacterium tuberculosis LAM (antiserum, Rabbit), NR-13821, was obtained through BEI Resources, NIAID, NIH, USA. Antibodies against IRG1 and LAMP-1 were purchased from Abcam (UK) and BD Biosciences (USA), respectively. Alexa Fluor 488 and 647 secondary antibodies, Hoechst 33342 and LipidTox Deep Red were all obtained from ThermoFisher (USA). DAPI was purchased from Sigma-Aldrich (USA).

Infection for intracellular mycobacterial replication and Lipid Droplets (LDs) formation assays. $2 \times 10^{4}$ BMDM or $4 \times 10^{4} \mathrm{BMDC}$ were seeded per well in 384-well plates. After 12 hours incubation at $37^{\circ} \mathrm{C}$ with $5 \%$ $\mathrm{CO}_{2}$, LPS $(100 \mathrm{ng} / \mathrm{mL})$ and IFN-gamma $(50 \mathrm{ng} / \mathrm{mL})$ were added as positive control. After overnight incubation, cells were infected for $2 \mathrm{~h}$ with H37Rv-GFP at a MOI of 1. Cells were washed with RPMI-FBS and treated with amikacin $(50 \mu \mathrm{g} / \mathrm{mL})$ for $1 \mathrm{~h}$ in order to remove extracellular Mtb. Then, cells were washed twice with RPMI-FBS and incubated at $37^{\circ} \mathrm{C}$ with $5 \% \mathrm{CO}_{2}$.

For intracellular mycobacterial replication assay, 10\% formalin solution (Sigma-Aldrich) containing $10 \mu \mathrm{g} / \mathrm{mL}$ Hoechst 33342 (Life-Technologies) was replaced to each well at $2 \mathrm{~h}$ and $96 \mathrm{~h}$ post-infection. Plates were incubated at RT for 30 min, allowing staining and cell fixation. Cells were stored in DPBS supplemented with $1 \%$ FBS, until image acquisition.

For LD formation assay, cells were washed and fixed at $96 \mathrm{~h}$ post-infection, as previously described. Cells were washed twice with DBPS and intracellular LDs were stained with $25 \mu \mathrm{L}$ per well of 2000 -fold diluted HCS LipidTOX deep Red neutral lipid probe (Invitrogen) in PBS for $30 \mathrm{~min}$ at room temperature.

Image Acquisition. Image acquisitions were performed on an automated confocal microscope (Opera, PerkinElmer) using a 20x and 60x water objectives for intracellular mycobacterial replication and LD formation assays, respectively. The microscope was equipped with $405 \mathrm{~nm}, 488 \mathrm{~nm}, 561 \mathrm{~nm}$ and $640 \mathrm{~nm}$ excitation lasers. The emitted fluorescence was captured using three cameras associated with a set of filters covering a detection wavelength ranging from $450 \mathrm{~nm}$ to $690 \mathrm{~nm}$. Hoechst 33342 -stained nuclei were 
detected using the $405 \mathrm{~nm}$ laser with a 450/50-nm emission filter. Green or red signals, corresponding to H37Rv-GFP and H37Rv-DsRed, were recorded using $488 \mathrm{~nm}$ or $561 \mathrm{~nm}$ lasers with 540/75- or 600/40-nm emission filters, respectively. LipidTOX signal was detected using 630-nm excitation and 690-nm emission wavelengths.

Image-based analysis. For mycobacteria replication and LD generation quantification, images from the automated confocal microscope were analyzed using multi-parameter scripts developed using Columbus system (version 2.3.1; PerkinElmer) (Supplementary Tables 2 and 3).

\section{Cell detection and M. tuberculosis intracellular replication}

Segmentation algorithms were applied to input images to detect nuclei labeled by Hoechst 33342 (cyan) and the GFP signal of Mtb H37Rv (green) to determine infection and replication rates. Briefly, the host cell segmentation was performed using two different Hoechst signal intensities-a strong intensity corresponding to the nucleus and a weak intensity in cytoplasm —with the algorithm "Find Nuclei" and "Find Cytoplasm", as described previously (Song et al., 2017). GFP or DsRed signal intensities in a cell were used for the intracellular bacterial segmentation with the algorithm "Find Spots". The identified intracellular bacteria were quantified as intracellular Mtb area with number of pixels. Subsequently, population of infected cells was determined, and the increase of intracellular Mtb area, corresponding to intracellular mycobacterial replication, was calculated.

\section{Cell detection and quantification of $L D$ formation}

LDs labeled by LipidTox DeepRed (red), nuclei labeled by Hoechst 33342 (blue) and the GFP signal of Mtb H37Rv (green) were detected using segmentation algorithms applied to input image. Briefly, the host cell segmentation using Hoechst signal and LipidTox intensities was performed to detect nuclei and cell borders, respectively. Mtb and LDs were determined by applying masks, which were adapted to GFP and LipidTox dye signal intensities, respectively. Further filtering and refinement using the algorithm "Find Micronuclei" and based on size-to-signal intensity and area of LD candidates allowed specific selection of LDs, which were separated from out-of-focus and background signal intensities. The identified intracellular bacteria were quantified as intracellular Mtb area with number of pixels. Subsequently, population of 
infected $(M t b)$ and non-infected (NI) cells were determined, and the percentage of LD-positive cells and the average of LD number per cell were calculated.

Western Blotting. Latex bead-containing phagosomes (LBPs) were isolated as described previously (Pauwels et al. 2019). LBP pellets were lysed in 2\% (v/v) Triton X-100, $50 \mathrm{mM}$ Tris, pH 8.0, $10 \mathrm{mM}$ dithiothreitol, 2x protease inhibitor mixture (Roche, France) for 30 min on ice. Phagosomal lysates and total cell lysates $(\mathrm{TCL})$ were mixed with $5 x$ Laemmli sample buffer and boiled for $5 \mathrm{~min}$ at $95{ }^{\circ} \mathrm{C}$. Samples were loaded on 4-15\% Criterion TGX protein gels (Bio-Rad, USA) and run in $25 \mathrm{mM}$ Tris, $192 \mathrm{mM}$ glycine, 0.1\% (m/vol) SDS, pH 8.3, at 100 V. Proteins were transferred onto $0.2 \mu \mathrm{m}$ PVDF membranes by a Trans-Blot Turbo device (Bio-Rad, USA) at 2.5 A for 7 min. Equal loading of samples was controlled by Ponceau S staining. After transfer, membranes were blocked in $5 \%$ dry milk and incubated with primary antibodies and peroxidase-conjugated secondary antibodies. Bound antibodies were revealed using Chemiluminescence Blotting Substrate from Roche according to the manufacturers' directions.

Immunofluorescence. BMDMs were grown overnight on poly-L-lysine-coated glass coverslips the day before the infection. Cells were infected with $M t b \mathrm{H} 37 \mathrm{Rv}$-DsRed at an $\mathrm{MOI}=1$ for $24 \mathrm{~h}$. Subsequently, cells were washed three times with PBS and fixed in PBS $+4 \%$ paraformaldehyde $+4 \%$ sucrose, $\mathrm{pH} 7.4$, for 20 min at RT followed by quenching in PBS $+50 \mathrm{mM} \mathrm{NH} 4 \mathrm{Cl}$ for 10 min. Coverslips were labeled for IRG1 (Abcam, UK), DNA using DAPI (Sigma-Aldrich, USA) and F-actin using Alexa Fluor 680 phalloidin (ThermoFisher, USA). After extensive washing, the coverslips were post-fixed in $4 \%$ paraformaldehyde for $16 \mathrm{~h}$ and then mounted with ProLong Gold antifade reagent (ThermoFisher, USA). Images were acquired using a confocal microscope (Zeiss LSM880) equipped with a 63x objective (NA 1.4) and Zen imaging software (Zeiss, Germany).

Quantitative RT-PCR. BMDMs were grown in 6-well plates and RNA was isolated using the RNeasy Mini kit (Qiagen, Germany) following the manufacturer's instructions. RNA concentration was determined using the GE SimpliNano device (GE Healthcare, UK). Remaining DNA in samples was digested using the amplification grade DNase I kit (Sigma-Aldrich, USA) for 6 min at RT. The reaction was stopped by heat inactivation for $10 \mathrm{~min}$ at $70^{\circ} \mathrm{C}$. cDNA synthesis was achieved by reverse transcription using the SuperScript VILO kit (ThermoFisher, USA) following the manufacturer's instructions. qPCR was performed using the 
LightCycler 480 SYBR Green I reagent (Roche, France) with 20 ng cDNA per sample and the indicated primer pairs (Supplementary Table S1). qPCR reactions were measured by the QuantStudio 12K Flex system (Applied Biosystems, USA) using the following cycles: 2 min $50^{\circ} \mathrm{C}, 10$ min $95^{\circ} \mathrm{C}$ followed by 40 cycles of $15 \mathrm{~s} 95^{\circ} \mathrm{C}, 30 \mathrm{~s} 60^{\circ} \mathrm{C}$ and $30 \mathrm{~s} 72^{\circ} \mathrm{C}$.

Cytokine measurements. Concentrations of IL-1 $\alpha$, IL-1 $\beta$, IL-6, MCP-1 and TNF in cell culture supernatants were measured by cytometric bead array (CBA) using the 13-plex Mouse Inflammation Panel (BioLegend, USA) following the manufacturer's instructions.

Infection of mice and determination of bacterial burden. Eight to twelve-week-old C57BL/6NJ WT and IRG1/- mice ( $n=16$ per group) were inoculated with Mtb H37Rv (or PBS for control mice) via the intranasal (i.n) route $\left(10^{5} \mathrm{CFU} / 20 \mu \mathrm{l}\right)$ as described (Costa-Gouveia et al 2017). After infection, individual body weight and survival of mice were monitored. At indicated time post infection, mice were euthanized and targeted organs (lungs, spleen, liver and draining bronchial lymph node) were harvested for bacterial burden evaluation by colony forming units (CFU) enumeration. Organs were homogenized for 20 min in a tube containing $2.5 \mathrm{~mm}$ diameter glass beads and $1 \mathrm{ml}$ of PBS using the MM 400 mixer mill (Retsch $\mathrm{GmbH}$, Haan, Germany). Ten-fold serial dilutions (from $10^{-2}$ to $10^{-9}$ ) of each sample were plated onto $7 \mathrm{H} 11$ medium agar plate (Difco) supplemented with $10 \%$ oleic acid-albumin-dextrose-catalase (OADC, Difco). After a three-week growth period at $37^{\circ} \mathrm{C}$, CFUs were determined at the appropriate dilution allowing optimal colonies enumeration.

Histology by immunofluorescence. As described previously (Machelart et al. 2019), lungs were perfused and fixed overnight at $4^{\circ} \mathrm{C}$ with $10 \%$ neutral buffered Formalin solution (Sigma-Aldrich), washed in PBS, and incubated overnight at RT in a $20 \%$ PBS-sucrose solution. Tissues were then embedded in the TissueTek OCT compound (Sakura), frozen in liquid nitrogen, and cryostat sections (10 $\mu \mathrm{m})$ were prepared.

For staining, tissue sections were rehydrated in PBS and incubated in a PBS solution containing $1 \%$ blocking reagent (PBS-BR, Boeringer) for 20 min before incubation overnight at $4^{\circ} \mathrm{C}$ in $\mathrm{PBS}-\mathrm{BR}$ containing any of the following mAbs or reagents: DAPI nucleic acid (Molecular Probes), phalloidin Alexa fluor 488 (Molecular Probes), Allophycocyanin-coupled BM8 (anti-F4/80, Abcam), Fluorescein-coupled HL3 (anti-CD11c, BD Biosciences), Fluorescien-coupled 145-2C11 (anti-CD3, BD Biosciences), Phycoerythrin- 
coupled E50-2440 (anti-Siglec-F, BD Biosciences), Alexa fluor 647-coupled 1A8 (anti-Ly6G, Biolegend), Allopphycocyanin-coupled RA3-6B2 (anti-CD45/B220, BD Biosciences). Polyclonal anti-Mtb LAM (antiserum, Rabbit), NR-13821, was obtained through BEI Resources, NIAID, NIH, USA. 2 hours at RT incubation with Alexa fluor 568-coupled Donkey anti-Rabbit IgG (Life technologies) was added to reveal anti-Mtb LAM staining. Slides were mounted in Fluoro-Gel medium (Electron Microscopy Sciences). Labeled tissue sections were visualized with an Axiovert M200 inverted microscope (Zeiss, lena, Germany) equipped with a high-resolution mono-chrome camera (AxioCam HR, Zeiss). At least three slides were analyzed per organ from three different animals.

Flow cytometry. Harvested lungs and spleens were cut into small pieces and incubated for 1 hour at $37^{\circ} \mathrm{C}$ with a mix of DNAse I $(100 \mu \mathrm{g} / \mathrm{ml}$, Sigma-Aldrich) and collagenase D (400 U/ml, Roche). Lung cells were washed and filtered before being incubated with saturating doses of purified 2.4G2 (anti-mouse Fc receptor, ATCC) in $200 \mu \mathrm{l}$ PBS, $0.2 \%$ BSA, $0.02 \% \mathrm{NaN}_{3}$ (FACS buffer) for $20 \mathrm{~min}$ at $4{ }^{\circ} \mathrm{C}$. Various fluorescent monoclonal antibody combinations in FACS buffer were used to stain cells. Acquisitions were done on a FACS Canto II flow cytometer (Becton Dickinson) with the following mAbs: Fluorescein (FITC)-coupled 1452C11 (anti-CD3, BD Biosciences), FITC-coupled HL3 (anti-CD11c, Invitrogen), Phycoerythrine (PE)coupled M1/70 (anti-CD11b, BD Biosciences), PE-coupled 53-6.7 (anti-CD8a, BD Biosciences), Allophycocyanin (APC)-coupled BM8 (anti-F4/80, BD Biosciences), APC-coupled RM4-5 (anti-CD4, Biolegend), Brillant violet 421 (BV421)-coupled E50-2440 (anti-SiglecF, BD Biosciences), BV421-coupled M5 (anti-MHCII, BD Biosciences), PE/cyanine(Cy)7-coupled RA3-6B2 (anti-CD45/B220, BD Biosciences) and PE/Cy7-coupled 1 A8 (anti-Ly6G, Biolegend). Fixable viability dye Aqua (ThermoFisher) was used to gate viable cells.

\begin{tabular}{|c|c|}
\hline Cell type & Phenotype \\
\hline Neutrophils & CD11b+ Ly6G+ \\
\hline Dendritic cells & $\mathrm{CD} 11 \mathrm{~b}^{+} \mathrm{CD} 11 \mathrm{c}^{+} \mathrm{F} 4 / 80^{-}$ \\
\hline Alveolar macrophages & $\mathrm{F} 4 / 80^{+}$SiglecF ${ }^{+} \mathrm{CD} 11 \mathrm{c}^{+}$ \\
\hline Interstitial macrophages & $\mathrm{F} 4 / 80^{+}$SiglecF- CD11 $\mathrm{c}^{\mathrm{int}}$ \\
\hline Eosinophils & $\mathrm{F} 4 / 80^{+}$SiglecF+ CD11 $\mathrm{C}^{-}$ \\
\hline CD4 T cells & $\mathrm{CD}^{+} \mathrm{CD}^{+}$ \\
\hline CD8 T cells & $\mathrm{CD}^{+} \mathrm{CD}^{+}$ \\
\hline B cells & $\mathrm{B} 220^{+} \mathrm{MHCll}^{+}$ \\
\hline
\end{tabular}


Statistics. All analyses and histograms were performed using GraphPad Prism 7 software. Significance of obtained results was tested using Mantel-Cox test (survival of Mtb-infected mice) and by Mann-Whitney test (Plating of CFU of different organs, immune cell profiling). Differences in the mean between two groups were analyzed using Student's t-test (in vitro replication and LD experiments). Indicated symbols of *, ** and ${ }^{* * *}$ denote $p<0.05, p<0.01$ and $p<0.001$, respectively.

\section{Acknowledgments}

We gratefully acknowledge Isabelle Ricard, Alexandre Vandeputte, Ruxandra Gref, Alain Baulard, Muriel Pichavant, Jérôme Kluza, William Laine, Gerald Larrouy-Maumus and Martin Cohen-Gonsaud for technical assistance and helpful discussions. We thank Nicolas Vandenabeele and Robin Prath for BSL-3 animal facility assistance. We kindly thank Carine Rouanet for providing titrated aliquots of Mycobacterium bovis BCG (1173P2 strain). We acknowledge the PICT-IBiSA and Frank Lafont from BiCEL for providing access to microscopy equipment. Financial support for this work was provided by the European Community (CycloNHit n 608407, ERC-STG INTRACELLTB ${ }^{\circ}$ 260901), the Agence Nationale de la Recherche (ANR10-EQPX-04-01, ANR-14-CE08-0017, ANR-16-CE35-0009), the EMBO Young Investigator Program, the Feder (12001407 (D-AL) Equipex Imaginex BioMed), the I-SITE ULNE Foundation (ERC Generator Grant) and the Fondation pour la Recherche Medicale (SPF20170938709). The funders had no role in study design, data collection and analysis, decision to publish, or preparation of the manuscript. 


\section{References}

Alloatti A, Kotsias F, Pauwels AM, Carpier JM, Jouve M, Timmerman E, Pace L, Vargas P, Maurin M, Gehrmann U, Joannas L, Vivar OI, Lennon-Duménil AM, Savina A, Gevaert K, Beyaert R, Hoffmann E, Amigorena S. 2015. Toll-like Receptor 4 Engagement on Dendritic Cells Restrains Phago-Lysosome Fusion and Promotes Cross-Presentation of Antigens. Immunity 43:1087-1100.

Andersen P, Scriba TJ. 2019. Moving tuberculosis vaccines from theory to practice. Nat Rev Immunol 19:550-562.

Baker JJ, Dechow SJ, Abramovitch RB. 2019. Acid Fasting: Modulation of Mycobacterium tuberculosis Metabolism at Acidic pH. Trends Microbiol doi:10.1016/j.tim.2019.06.005.

Bambouskova M, Gorvel L, Lampropoulou V, Sergushichev A, Loginicheva E, Johnson K, Korenfeld D, Mathyer ME, Kim H, Huang LH, Duncan D, Bregman H, Keskin A, Santeford A, Apte RS, Sehgal R, Johnson B, Amarasinghe GK, Soares MP, Satoh T, Akira S, Hai T, de Guzman Strong C, Auclair K, Roddy TP, Biller SA, Jovanovic M, Klechevsky E, Stewart KM, Randolph GJ, Artyomov MN. 2018. Electrophilic properties of itaconate and derivatives regulate the lkappaBzeta-ATF3 inflammatory axis. Nature 556:501-504.

Basler T, Jeckstadt S, Valentin-Weigand P, Goethe R. 2006. Mycobacterium paratuberculosis, Mycobacterium smegmatis, and lipopolysaccharide induce different transcriptional and post-transcriptional regulation of the IRG1 gene in murine macrophages. $J$ Leukoc Biol 79:628-638.

Bernut A, Dupont C, Ogryzko NV, Neyret A, Herrmann JL, Floto RA, Renshaw SA, Kremer L. 2019. CFTR Protects against Mycobacterium abscessus Infection by Fine-Tuning Host Oxidative Defenses. Cell Rep 26:1828-1840.

Bhatt-Wessel B, Jordan TW, Miller JH, Peng L. 2018. Role of DGAT enzymes in triacylglycerol metabolism. Arch Biochem Biophys 655:1-11.

Braverman J, Sogi KM, Benjamin D, Nomura DK, Stanley SA. 2016. HIF-1alpha Is an Essential Mediator of IFN-gamma-Dependent Immunity to Mycobacterium tuberculosis. J Immunol 197:1287-1297.

Bougnères L, Helft J, Tiwari S, Vargas $P$, Chang BH, Chan L, Campisi L, Lauvau G, Hugues S, Kumar $P$, Kamphorst AO, Dumenil AM, Nussenzweig M, MacMicking JD, Amigorena S, Guermonprez P. 2009. A role for lipid bodies in the cross-presentation of phagocytosed antigens by MHC class I in dendritic cells. Immunity 31:232-244.

Buter J, Cheng TY, Ghanem M, Grootemaat AE, Raman S, Feng X, Plantijn AR, Ennis T, Wang J, Cotton RN, Layre E, Ramnarine AK, Mayfield JA, Young DC, Jezek Martinot A, Siddiqi N, Wakabayashi S, Botella H, Calderon R, Murray M, Ehrt S, Snider BB, Reed MB, Oldfield E, Tan S, Rubin EJ, Behr MA, van der Wel NN, Minnaard AJ, Moody DB. 2019. Mycobacterium tuberculosis releases an antacid that remodels phagosomes. Nat Chem Biol 15:889-899.

Cadena AM, Fortune SM. 2017. Heterogeneity in tuberculosis. Nat Rev Immunol 17:691-702.

Christophe T, Jackson M, Jeon HK, Fenistein D, Contreras-Dominguez M, Kim J, Genovesio A, Carralot JP, Ewann F, Kim EH, Lee SY, Kang S, Seo MJ, Park EJ, Skovierová H, Pham H, Riccardi G, Nam JY, Marsollier L, Kempf M, Joly-Guillou ML, Oh T, Shin WK, No Z, Nehrbass U, Brosch R, Cole ST, Brodin P. 2009. High content screening identifies decaprenyl-phosphoribose 2 ' epimerase as a target for intracellular antimycobacterial inhibitors. PLoS Pathog 5:e1000645. 
Costa-Gouveia J, Pancani E, Jouny S, Machelart A, Delorme V, Salzano G, lantomasi R, Piveteau C, Queval CJ, Song OR, Flipo M, Deprez B, Saint-André JP, Hureaux J, Majlessi L, Willand N, Baulard A, Brodin P, Gref R. 2017. Combination therapy for tuberculosis treatment: pulmonary administration of ethionamide and booster co-loaded nanoparticles. Sci Rep 7:5390.

Deboosère N, lantomasi R, Queval CJ, Song OR, Deloison G, Jouny S, Debrie AS, Chamaillard M, Nigou J, Cohen-Gonsaud M, Locht C, Brodin P, Veyron-Churlet R. 2017. LppM impact on the colonization of macrophages by Mycobacterium tuberculosis. Cell Microbiol 19:e12619.

den Brok MH, Raaijmakers TK, Collado-Camps E, Adema GJ. 2018. Lipid Droplets as Immune Modulators in Myeloid Cells. Trends Immunol 39:380-392.

Di A, Brown ME, Deriy LV, Li C, Szeto FL, Chen Y, Huang P, Tong J, Naren AP, Bindokas V, Palfrey HC, Nelson DJ. 2006. CFTR regulates phagosome acidification in macrophages and alters bactericidal activity. Nat Cell Biol 8:933-944.

Elamin AA, Stehr M, Spallek R, Rohde M, Singh M. 2011. The Mycobacterium tuberculosis Ag85A is a novel diacylglycerol acyltransferase involved in lipid body formation. Mol Microbiol 81:1577-1592.

Escoll P, Buchrieser C. 2019. Metabolic reprogramming: an innate cellular defence mechanism against intracellular bacteria? Curr Opin Immunol 60:117-123.

Hoffmann E, Kotsias F, Visentin G, Bruhns P, Savina A, Amigorena S. 2012. Autonomous phagosomal degradation and antigen presentation in dendritic cells. Proc Natl Acad Sci U S A 109:14556-14561.

Jayashankar L, Hafner R. 2016. Adjunct Strategies for Tuberculosis Vaccines: Modulating Key Immune Cell Regulatory Mechanisms to Potentiate Vaccination. Front Immunol 7:577.

Kaufmann E, Sanz J, Dunn JL, Khan N, Mendonça LE, Pacis A, Tzelepis F, Pernet E, Dumaine A, Grenier JC, Mailhot-Léonard F, Ahmed E, Belle J, Besla R, Mazer B, King IL, Nijnik A, Robbins CS, Barreiro LB, Divangahi M. 2018. BCG Educates Hematopoietic Stem Cells to Generate Protective Innate Immunity against Tuberculosis. Cell 172:176-190.

Knight M, Braverman J, Asfaha K, Gronert K, Stanley S. 2018. Lipid droplet formation in Mycobacterium tuberculosis infected macrophages requires IFN-gamma/HIF-1alpha signaling and supports host defense. PLoS Pathog 14:e1006874.

Knight M, Stanley S. 2019. HIF-1alpha as a central mediator of cellular resistance to intracellular pathogens. Curr Opin Immunol 60:111-116.

Koivunen P, Hirsilä M, Remes AM, Hassinen IE, Kivirikko KI, Myllyharju J. 2007. Inhibition of hypoxiainducible factor (HIF) hydroxylases by citric acid cycle intermediates: possible links between cell metabolism and stabilization of HIF. J Biol Chem 282:4524-4532.

Lampropoulou V, Sergushichev A, Bambouskova M, Nair S, Vincent EE, Loginicheva E, CervantesBarragan L, Ma X, Huang SC, Griss T, Weinheimer CJ, Khader S, Randolph GJ, Pearce EJ, Jones RG, Diwan A, Diamond MS, Artyomov MN. 2016. Itaconate Links Inhibition of Succinate Dehydrogenase with Macrophage Metabolic Remodeling and Regulation of Inflammation. Cell Metab 24:158-166.

Machelart A, Song OR, Hoffmann E, Brodin P. 2017. Host-directed therapies offer novel opportunities for the fight against tuberculosis. Drug Discov Today 22:1250-1257.

McKinney JD, Höner zu Bentrup K, Muñoz-Elías EJ, Miczak A, Chen B, Chan WT, Swenson D, Sacchettini JC, Jacobs WR Jr, Russell DG. 2000. Persistence of Mycobacterium tuberculosis in macrophages and mice requires the glyoxylate shunt enzyme isocitrate lyase. Nature 406:735-738. 
Meunier I, Kaufmann E, Downey J, Divangahi M. 2017. Unravelling the networks dictating host resistance versus tolerance during pulmonary infections. Cell Tissue Res 367:525-536.

Michelucci A, Cordes T, Ghelfi J, Pailot A, Reiling N, Goldmann O, Binz T, Wegner A, Tallam A, Rausell A, Buttini M, Linster CL, Medina E, Balling R, Hiller K. 2013. Immune-responsive gene 1 protein links metabolism to immunity by catalyzing itaconic acid production. Proc Natl Acad Sci U S A 110:7820-7825.

Mills EL, Ryan DG, Prag HA, Dikovskaya D, Menon D, Zaslona Z, Jedrychowski MP, Costa ASH, Higgins M, Hams E, Szpyt J, Runtsch MC, King MS, McGouran JF, Fischer R, Kessler BM, McGettrick AF, Hughes MM, Carroll RG, Booty LM, Knatko EV, Meakin PJ, Ashford MLJ, Modis LK, Brunori G, Sévin DC, Fallon PG, Caldwell ST, Kunji ERS, Chouchani ET, Frezza C, Dinkova-Kostova AT, Hartley RC, Murphy MP, O'Neill LA. 2018. Itaconate is an anti-inflammatory metabolite that activates Nrf2 via alkylation of KEAP1. Nature 556:113-117.

Nair S, Huynh JP, Lampropoulou V, Loginicheva E, Esaulova E, Gounder AP, Boon ACM, Schwarzkopf EA, Bradstreet TR, Edelson BT, Artyomov MN, Stallings CL, Diamond MS. 2018. Irg1 expression in myeloid cells prevents immunopathology during M. tuberculosis infection. J Exp Med 215:1035-1045.

Naujoks J, Tabeling C, Dill BD, Hoffmann C, Brown AS, Kunze M, Kempa S, Peter A, Mollenkopf HJ, Dorhoi A, Kershaw O, Gruber AD, Sander LE, Witzenrath M, Herold S, Nerlich A, Hocke AC, van Driel I, Suttorp N, Bedoui S, Hilbi H, Trost M, Opitz B. 2016. IFNs Modify the Proteome of Legionella-Containing Vacuoles and Restrict Infection Via IRG1-Derived Itaconic Acid. PLoS Pathog 12:e1005408.

O'Neill LA, Pearce EJ. 2016. Immunometabolism governs dendritic cell and macrophage function. $J$ Exp Med 213:15-23.

O'Neill LAJ, Artyomov MN. 2019. Itaconate: the poster child of metabolic reprogramming in macrophage function. Nat Rev Immunol 19:273-281.

Pauwels AM, Härtlova A, Peltier J, Driege Y, Baudelet G, Brodin P, Trost M, Beyaert R, Hoffmann E 2019. Spatiotemporal Changes of the Phagosomal Proteome in Dendritic Cells in Response to LPS Stimulation. Mol Cell Proteomics 18:909-922.

Peyron P, Vaubourgeix J, Poquet Y, Levillain F, Botanch C, Bardou F, Daffé M, Emile JF, Marchou B, Cardona PJ, de Chastellier C, Altare F. 2008. Foamy macrophages from tuberculous patients' granulomas constitute a nutrient-rich reservoir for M. tuberculosis persistence. PLoS Pathog 4:e1000204.

Philips JA, Ernst JD. 2012. Tuberculosis pathogenesis and immunity. Ann Rev Pathol 7:353-384.

Price JV, Russo D, Ji DX, Chavez R, DiPeso L, Lee AY-F, Coers J, Vance RE. 2019. IRG1 and iNOS act redundantly with other interferon gamma-induced factors to restrict intracellular replication of Legionella pneumophila. bioRxiv doi.org/10.1101/731182.

Queval CJ, Song OR, Deboosère N, Delorme V, Debrie AS, lantomasi R, Veyron-Churlet R, Jouny S, Redhage K, Deloison G, Baulard A, Chamaillard M, Locht C, Brodin P. 2016. STAT3 Represses Nitric Oxide Synthesis in Human Macrophages upon Mycobacterium tuberculosis Infection. Sci Rep 6:29297.

Queval CJ, Song OR, Carralot JP, Saliou JM, Bongiovanni A, Deloison G, Deboosère N, Jouny S, lantomasi R, Delorme V, Debrie AS, Park SJ, Gouveia JC, Tomavo S, Brosch R, Yoshimura A, Yeramian E, Brodin P. 2017. Mycobacterium tuberculosis Controls Phagosomal Acidification by Targeting $\mathrm{CISH}-$ Mediated Signaling. Cell Rep 20:3188-3198.

Ranjbar S, Haridas V, Jasenosky LD, Falvo JV, Goldfeld AE. 2015. A Role for IFITM Proteins in Restriction of Mycobacterium tuberculosis Infection. Cell Rep 13:874-883. 
Raze D, Verwaerde C, Deloison G, Werkmeister E, Coupin B, Loyens M, Brodin P, Rouanet C, Locht C. 2018. Heparin-Binding Hemagglutinin Adhesin (HBHA) Is Involved in Intracytosolic Lipid Inclusions Formation in Mycobacteria. Front Microbiol 9:2258.

Riquelme SA, Lozano C, Moustafa AM, Liimatta K, Tomlinson KL, Britto C, Khanal S, Gill SK, Narechania A, Azcona-Gutiérrez JM, DiMango E, Saénz Y, Planet P, Prince A. 2019. CFTR-PTEN-dependent mitochondrial metabolic dysfunction promotes Pseudomonas aeruginosa airway infection. Sci Trans/ Med 11:eaav4634.

Russell DG, Cardona PJ, Kim MJ, Allain S, Altare F. 2009. Foamy macrophages and the progression of the human tuberculosis granuloma. Nat Immunol 10:943-948.

Russell DG, Huang L, VanderVen BC. 2019. Immunometabolism at the interface between macrophages and pathogens. Nat Rev Immunol 19:291-304.

Shi L, Jiang Q, Bushkin Y, Subbian S, Tyagi S. 2019. Biphasic Dynamics of Macrophage Immunometabolism during Mycobacterium tuberculosis Infection. MBio 10:e02550-18.

Singh V, Jamwal S, Jain R, Verma P, Gokhale R, Rao KV. 2012. Mycobacterium tuberculosis-driven targeted recalibration of macrophage lipid homeostasis promotes the foamy phenotype. Cell Host Microbe 12:669-681.

Song OR, Deboosere N, Delorme V, Queval CJ, Deloison G, Werkmeister E, Lafont F, Baulard A, lantomasi $\mathrm{R}$, Brodin P 2017. Phenotypic assays for Mycobacterium tuberculosis infection. Cytometry A 91:983-994.

Sturgill-Koszycki S, Schlesinger PH, Chakraborty P, Haddix PL, Collins HL, Fok AK, Allen RD, Gluck SL, Heuser J, Russell DG. 1994. Lack of acidification in Mycobacterium phagosomes produced by exclusion of the vesicular proton-ATPase. Science 263:678-681.

Tallam A, Perumal TM, Antony PM, Jäger C, Fritz JV, Vallar L, Balling R, Del Sol A, Michelucci A. 2016. Gene Regulatory Network Inference of Immunoresponsive Gene 1 (IRG1) Identifies Interferon Regulatory Factor 1 (IRF1) as Its Transcriptional Regulator in Mammalian Macrophages. PloS One 11:e0149050.

Tan S, Sukumar N, Abramovitch RB, Parish T, Russell DG. 2013. Mycobacterium tuberculosis responds to chloride and pH as synergistic cues to the immune status of its host cell. PLoS Pathog 9:e1003282.

Tannahill GM, Curtis AM, Adamik J, Palsson-McDermott EM, McGettrick AF, Goel G, Frezza C, Bernard NJ, Kelly B, Foley NH, Zheng L, Gardet A, Tong Z, Jany SS, Corr SC, Haneklaus M, Caffrey BE, Pierce K, Walmsley S, Beasley FC, Cummins E, Nizet V, Whyte M, Taylor CT, Lin H, Masters SL, Gottlieb E, Kelly VP, Clish C, Auron PE, Xavier RJ, O'Neill LA. 2013. Succinate is an inflammatory signal that induces IL1 beta through HIF-1alpha. Nature 496:238-242.

WHO 2018. Global Tuberculosis Report 2018. https://www.who.int/tb/publications/global_report/en/

Wong D, Bach H, Sun J, Hmama Z, Av-Gay Y. 2011. Mycobacterium tuberculosis protein tyrosine phosphatase (PtpA) excludes host vacuolar-H+-ATPase to inhibit phagosome acidification. Proc Natl Acad Sci U S A 108:19371-19376. 


\section{Figures}

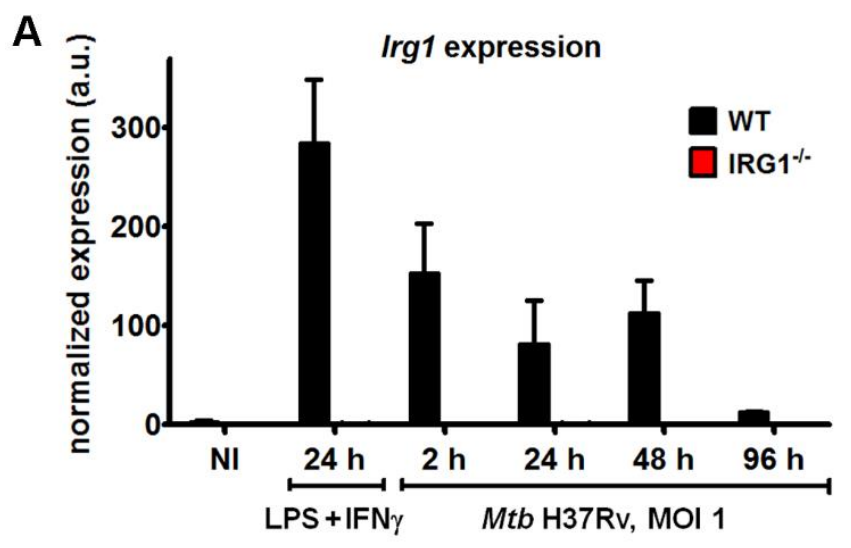

B

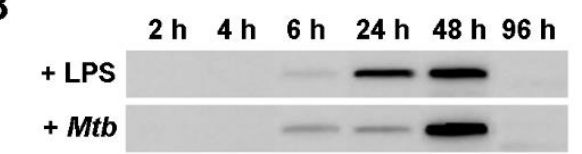

C

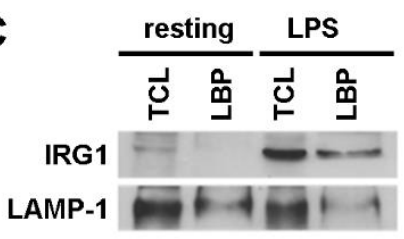

D
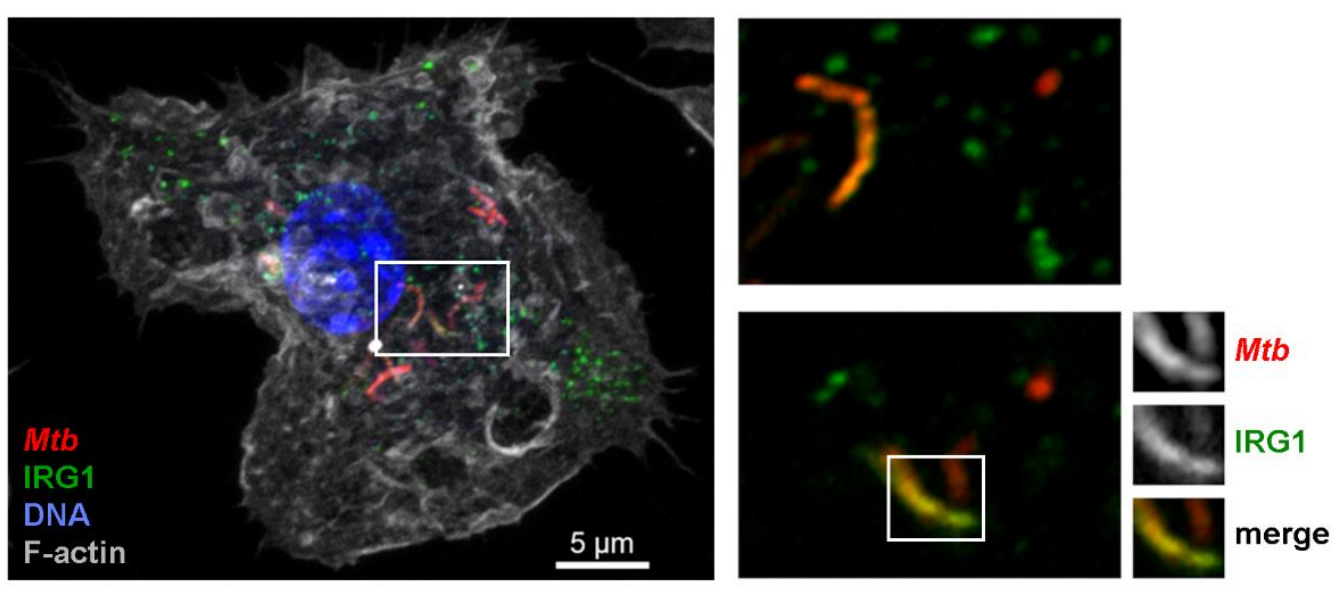

Figure 1. IRG1 is induced at transcriptional level subsequent to Mtb infection and is recruited to Mtb-containing phagosomes. A) WT BMDMs and IRG1-deficient BMDMs were either treated with 100 $\mathrm{ng} / \mathrm{ml}$ LPS and $20 \mathrm{ng} / \mathrm{ml} \mathrm{IFN} \gamma$ or infected with $M t b \mathrm{H} 37 \mathrm{Rv}$ at MOI 1 for the indicated time points. Noninfected ( $\mathrm{NI}$ ) cells served as control. Transcription of Irg1 was assessed by quantitative RT-PCR and normalized to the expression of Gapdh, used in all samples as housekeeping gene. Shown are mean \pm SEM obtained from BMDMs of three different mice. B) Expression of IRG1 protein in total cell lysates as detected by western blotting applied to WT BMDMs treated with $100 \mathrm{ng} / \mathrm{ml}$ LPS or infected with Mtb H37Rv at the indicated time points. C) Detection of IRG1 and LAMP-1 in total cell lysates (TCL) or purified latex bead-containing phagosomes (LBP) as determined by western blotting comparing WT BMDCs, either at resting state (left) or $16 \mathrm{~h}$ after the addition of $100 \mathrm{ng} / \mathrm{ml}$ LPS (right). D) Confocal image of the subcellular localization of Mtb H37Rv-DsRed (red) and IRG1 (green) in WT BMDM at $24 \mathrm{~h}$ post-infection. The nucleus was labeled with DAPI (blue), while F-actin was visualized by Phalloidin staining (gray). Insets (right panel) depict different focal planes of the same area showing co-localization of IRG1 to Mtb vacuoles. 
A
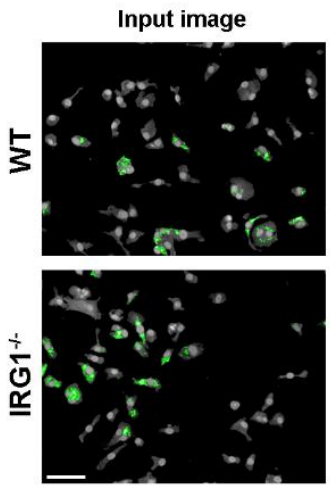

B

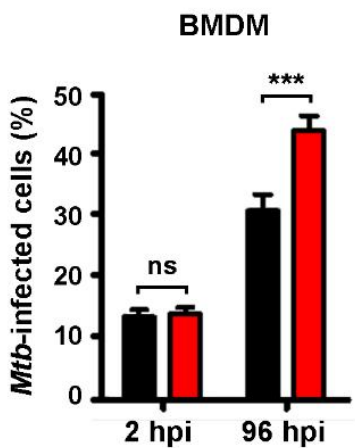

Nuclei detection
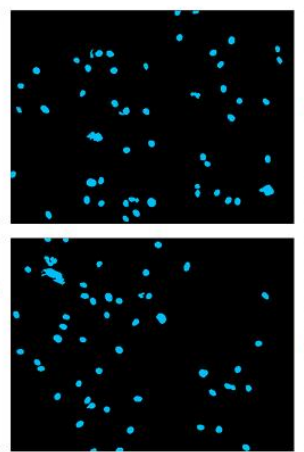

BMDC
Cell selection
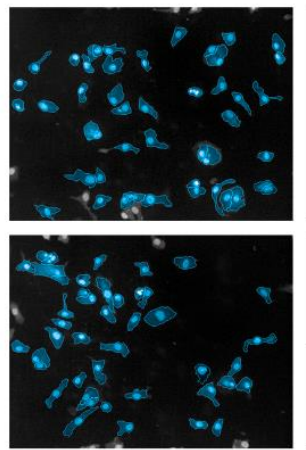

C
Mtb detection
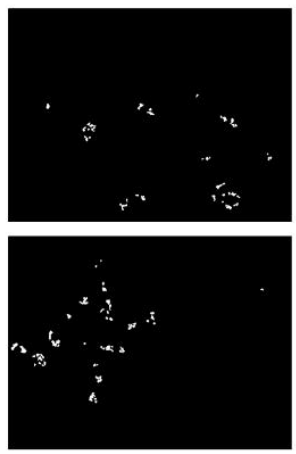

BMDM
Infected cell selection
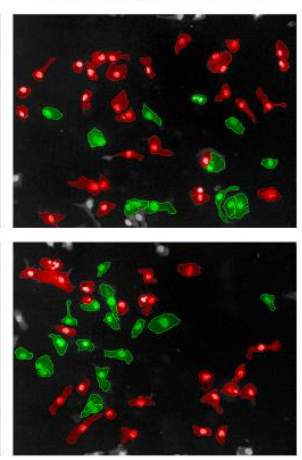

BMDC
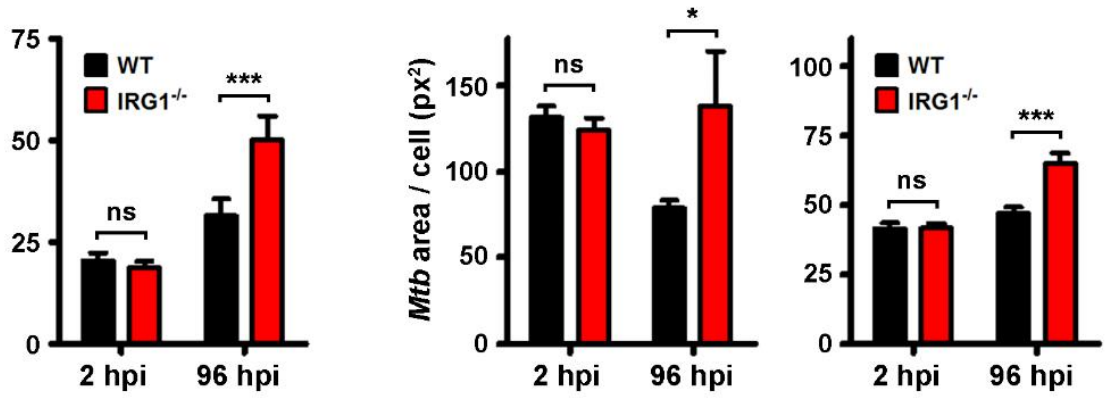

Figure 2. Replication of $M t b$ is increased in IRG1/- macrophages and dendritic cells. BMDMs and BMDCs were grown in 384-well plates, infected with Mtb H37Rv-GFP (MOI=1) and analyzed by automated confocal microscopy. A) Workflow of the applied multiparametric image analysis pipeline using Columbus software. Shown are representative images of WT BMDMs (upper panel) and IRG1-1- BMDMs (lower panel) at $96 \mathrm{~h}$ post-infection (hpi). Segmentation algorithms were applied to input images to detect nuclei labeled by Hoechst 33342 (cyan) and the GFP signal of Mtb H37Rv (green) to determine infection and replication rates. In the right panel, infected cells are depicted in green, while non-infected cells are shown in red. Cells only partially shown in the microscopy field (depicted in gray) were excluded from analysis. Bar: $50 \mu \mathrm{m}$. B) Histograms displaying the percentage of infected BMDMs (left panel) and BMDCs (right panel) at 2 hpi and 96 hpi. C) Histograms showing the bacterial area per infected BMDM (left panel) and infected BMDC (right panel) at both time points, which directly correlates with the number of Mtb per infected cell. Shown are mean \pm SEM of at least 6 analyzed wells per condition ( $n>500$ cells) of one representative out of three independent experiments. ns: non-significant, ${ }^{*} P$ value $<0.05$, ${ }^{* * *} P$ value $<0.001$, as determined by Student's t-test. 
A

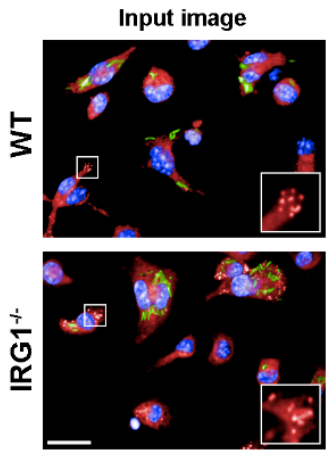

B

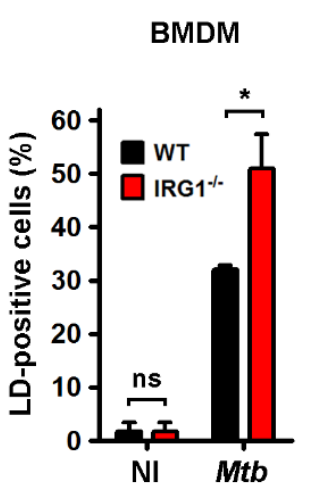

Cell selection

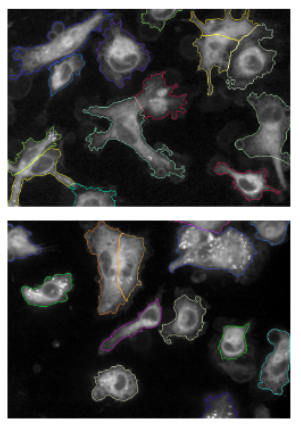

BMDC

C
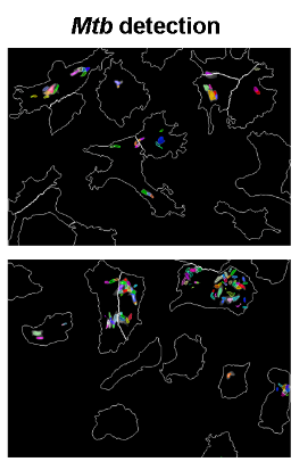

BMDM
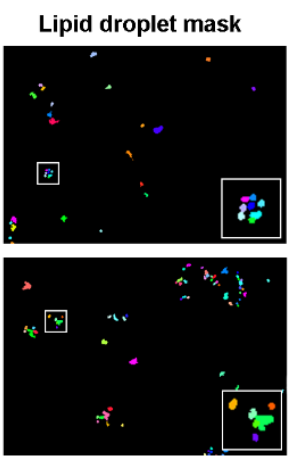

BMDC
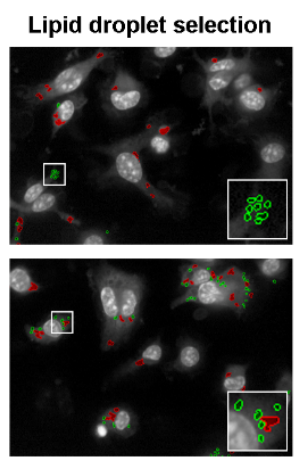

D

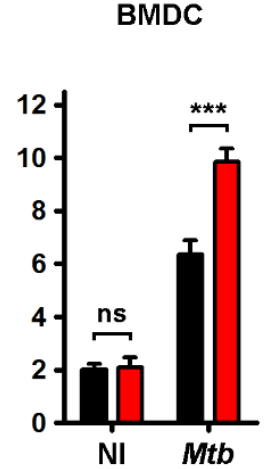

Figure 3. IRG1 deficiency is concomitant with increased amounts of lipid droplets in Mtb-infected phagocytes. BMDMs and BMDCs were grown in 384-well plates and infected with Mtb H37Rv-GFP (MOI = 1). At $96 \mathrm{hpi}$, cells were fixed, labeled and analyzed by automated confocal microscopy and multiparametric image analysis. A) Workflow of the applied image analysis pipeline using Columbus software to quantify lipid droplet (LD) generation. Shown are representative input images (left) of WT BMDM (upper panel) and IRG1-/ BMDM (lower panel) displaying LDs labeled by LipidTox DeepRed (red), nuclei labeled by Hoechst 33342 (blue) and the GFP signal of Mtb H37Rv (green). Segmentation algorithms were used to detect cell borders and Mtb followed by applying an LD mask, which was adapted to LipidTox dye signal intensities. Further filtering and refinement based on size-to-signal intensity allowed specific selection of LDs (green circles in the right images), which were separated from out-of-focus and background signal intensities (red circles in the right images). Insets show magnifications of LDs of example cells. Bar: $20 \mu \mathrm{m}$. B) Histograms depicting the percentage of LD-positive non-infected (NI) and Mtb-infected BMDMs (left panel) and BMDCs (right panel). C) Histograms showing the average LD number per cell for both cell types. Shown are mean \pm SEM of at least 6 analyzed wells per condition ( $n>400$ cells) of one representative out of three independent experiments. D) LD numbers of BMDMs were also counted manually in a blinded fashion ( $n=100$ cells) to verify accuracy of the automated image analysis. Shown is the mean (red) of LD numbers in infected BMDMs at 96 hpi. ns: non-significant, ${ }^{*} P$ value $<0.05$, ${ }^{* *} P$ value $<0.01$, ${ }^{* * *} P$ value $<0.001$, as determined by Student's t-test. 
A

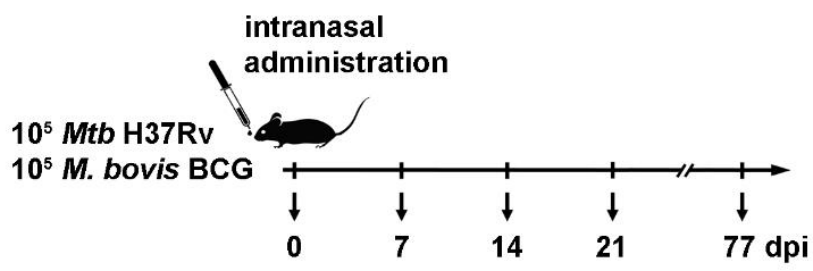

B

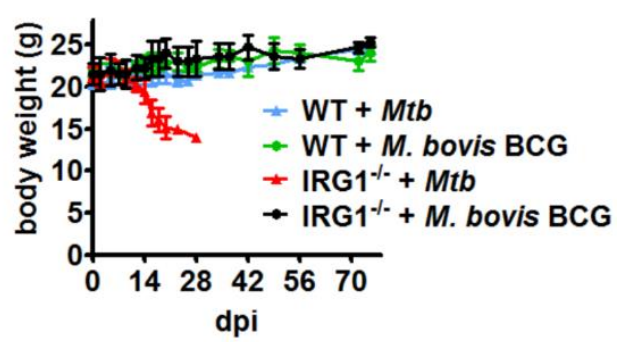

C

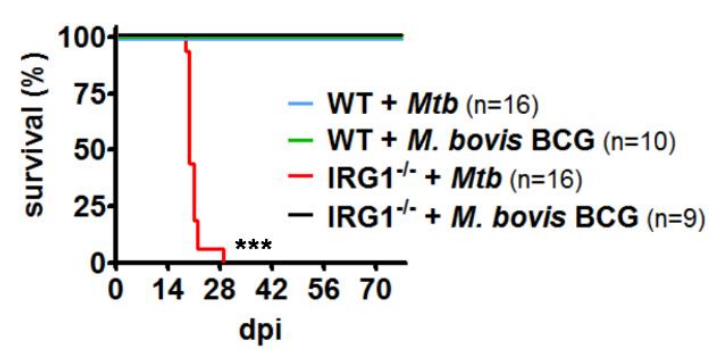

D

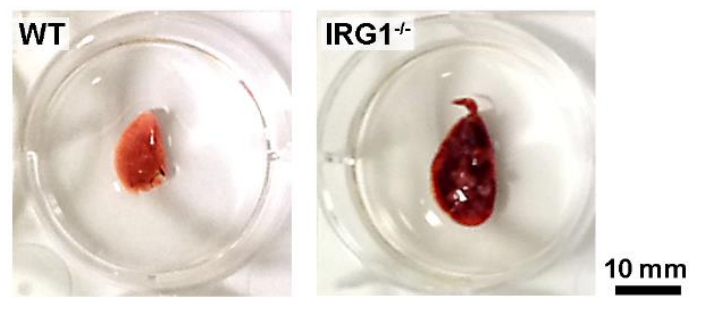

E

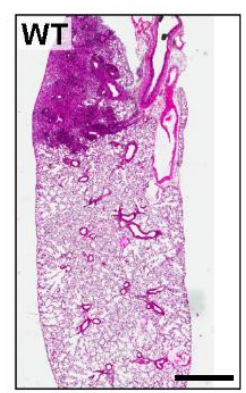

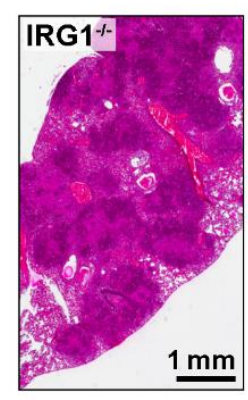

$\mathbf{F}$

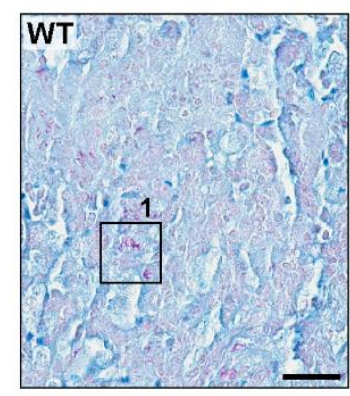

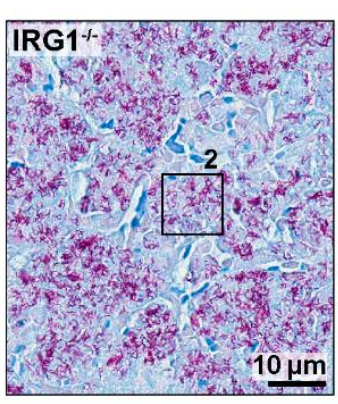

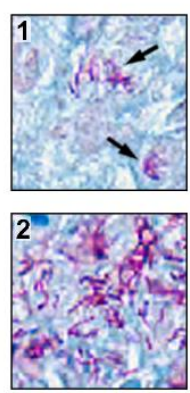

Figure 4. IRG1/- mice are highly susceptible to $M$ tb infection but not to $M$. bovis BCG. A) Workflow of mycobacterial infection experiments indicating different read-out time points at days post-infection (dpi). B-C) Changes in body weight of female WT and IRG1- mice (B) and their survival rates (C) after intranasal inoculation by $M t b H 37 R v$ and $M$. bovis BCG. Shown are mean \pm SEM. ${ }^{* * *} P$ value $<0.001$, as determined by Mantel-Cox test. D) Photographs of representative examples of the left lung lobe of WT and IRG1/- mice at $21 \mathrm{dpi}$ by Mtb H37Rv. E) Immunopathology of mouse lungs $21 \mathrm{dpi}$ after Mtb H37Rv infection, as determined by hematoxylin phloxine saffron staining of histological sections. F) Images showing the mycobacterial load in lungs of WT and IRG1/- mice at 21 dpi by Mtb H37Rv, as estimated by acid-fast stain (Ziehl-Neelsen staining) of representative histological sections. Insets display labeled bacteria in purple (arrows). 
A

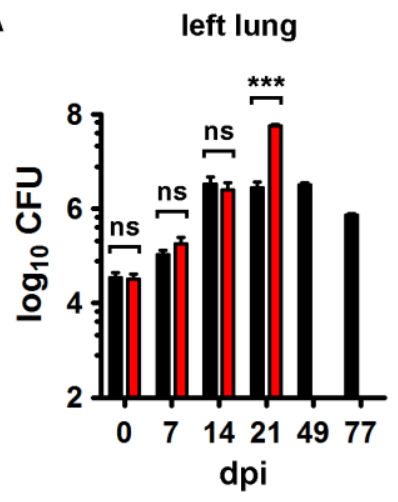

B

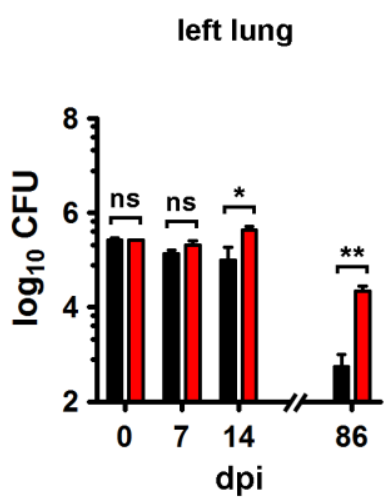

tracheobronchial lymph node

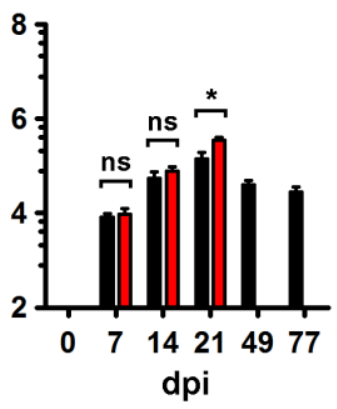

tracheobronchial lymph node

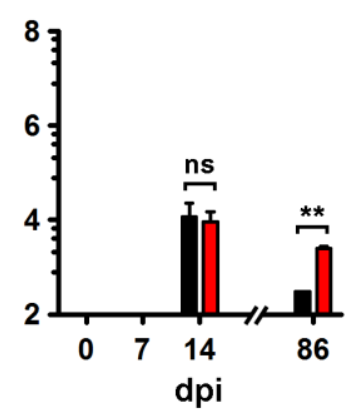

spleen

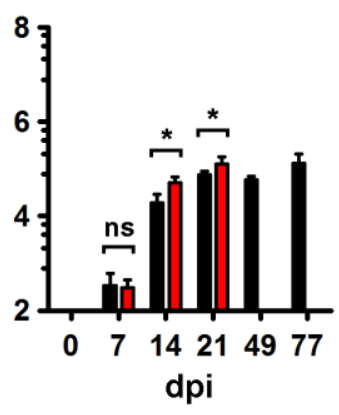

spleen

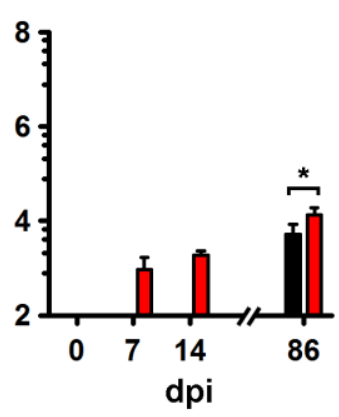

liver

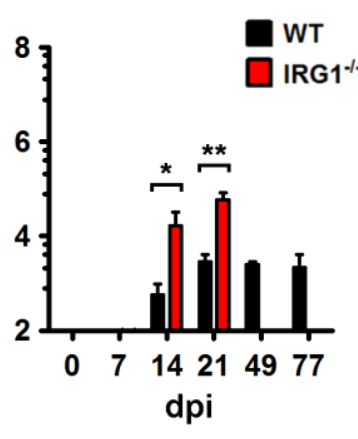

WT

IRG1 ${ }^{\text {- }}$

Figure 5. IRG1 ${ }^{-/}$mice are unable to eradicate $M$. bovis BCG infection. Organs of WT and IRG1 ${ }^{-/}$mice were analyzed after infection with $M t b \operatorname{H37Rv}(\mathbf{A})$ or $M$. bovis $B C G(B)$ at the indicated dpi. Mycobacterial load was determined by plating organ lysates and counting Colony-Forming Units (CFU) three weeks after plating. Shown are mean \pm SEM of at least three infected mice per condition. ns: non-significant, * $P$ value $<0.05,{ }^{* *} \mathrm{P}$ value $<0.01,{ }^{* \star} \mathrm{P}$ value $<0.001$, as determined by Mann-Whitney test. 
A

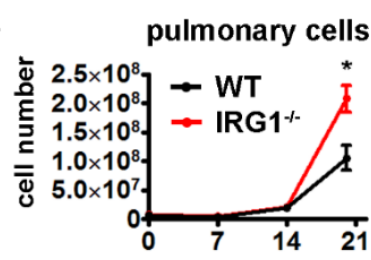

eosinophils

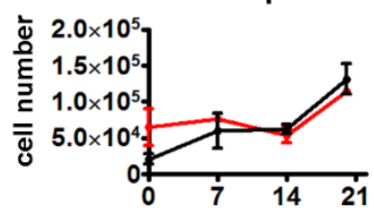

$\mathrm{CD4}^{+} \mathrm{T}$ cells

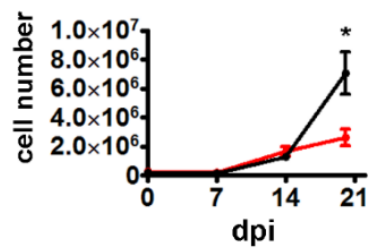

alveolar $M \emptyset$

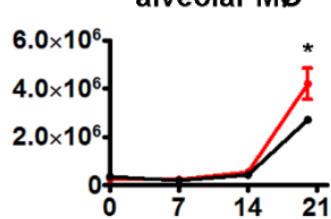

dendritic cells

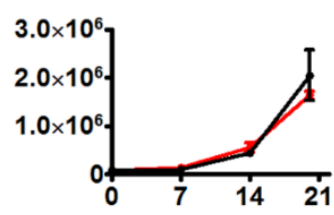

CD8 ${ }^{+} \mathrm{T}$ cells

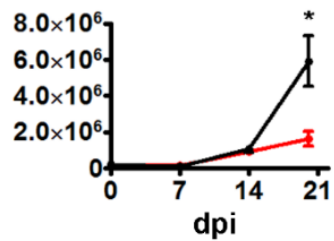

interstitial Mø

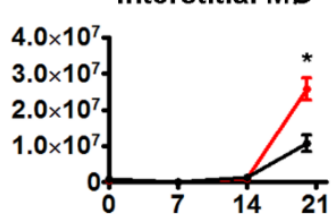

neutrophils

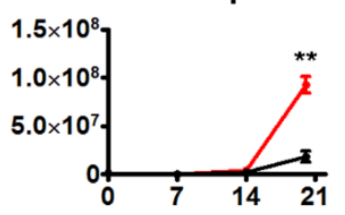

B lymphocytes

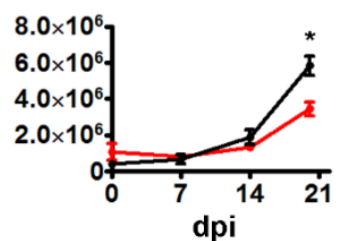

B
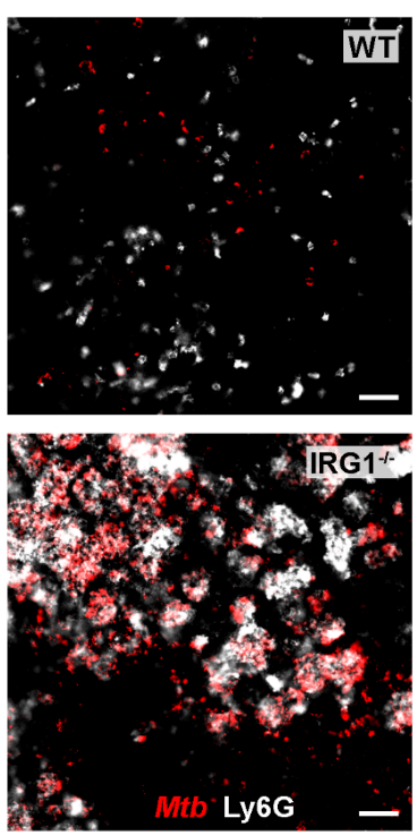

Figure 6. Comparative study of immune cell populations in Mtb-infected lungs of WT and IRG1/-

mice. A) Histograms depicting changes of cell numbers of diverse immune cell populations during the course of $M t b \mathrm{H} 37 \mathrm{Rv}$ infection, as determined by flow cytometry using specific cell surface markers. All cell numbers were normalized to the total cell number analyzed in each sample and were extrapolated to the whole organ. Shown are mean \pm SEM of cells obtained from three individual mice per group. ${ }^{*} \mathrm{P}$ value < $0.05,{ }^{* *} \mathrm{P}$ value $<0.01$, as determined by Mann-Whitney test. $\mathrm{M} \varnothing$ : macrophage. B) Representative images of lung tissue cryosections obtained from WT or IRG1\% mice at $21 \mathrm{dpi}$ and acquired by confocal microscopy. Mycobacteria (red) were labeled with a specific lipoarabinomannan (LAM) antibody, while neutrophils (white) were labeled with an antibody against Ly6G. Bar: $50 \mu \mathrm{m}$. 


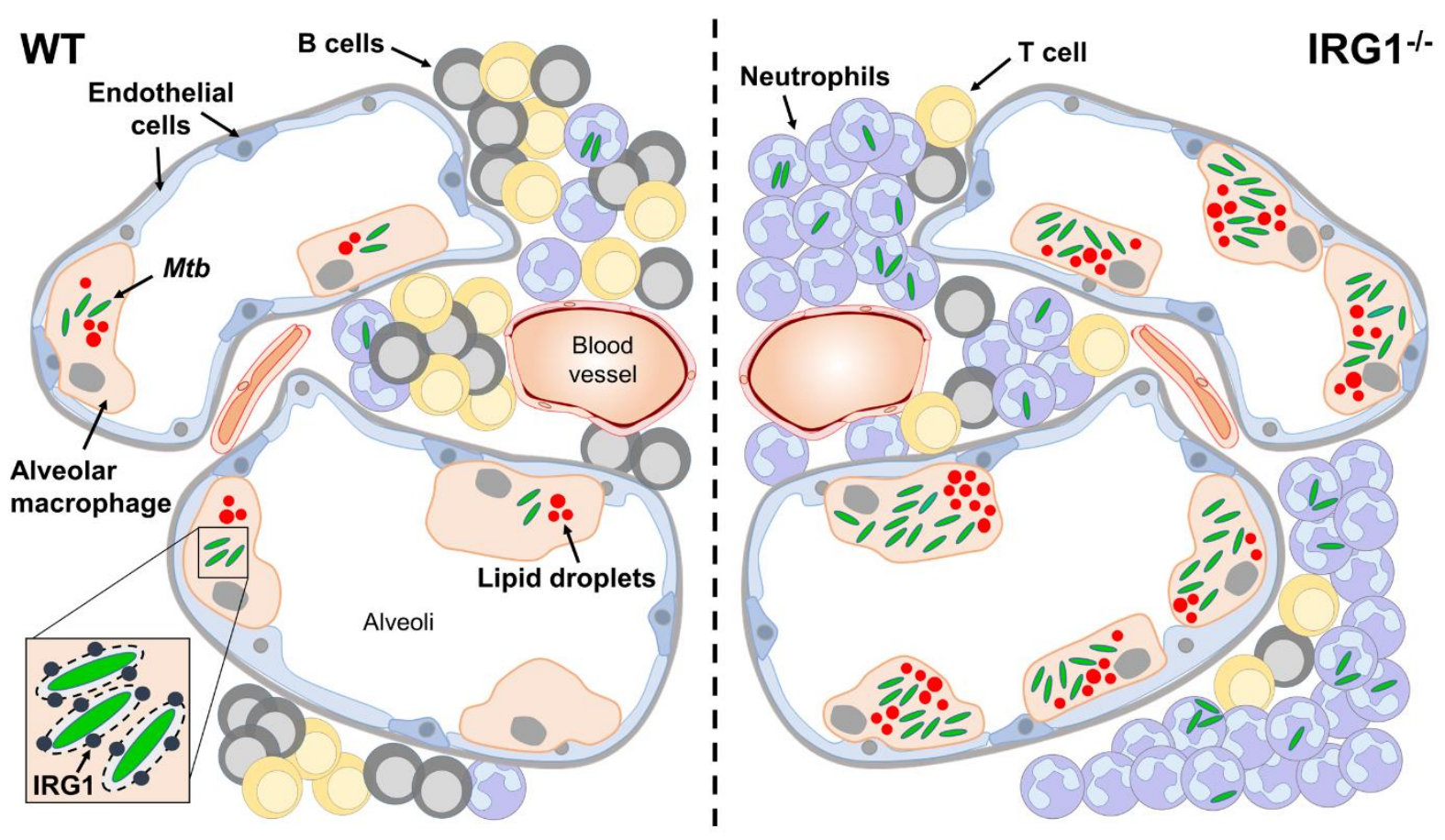

Figure 7. Induced expression of IRG1 during Mtb infection restricts formation of lipid droplets and intracellular pathogen growth. Infection of alveolar macrophages by Mtb, which leads to recruitment of IRG1 to Mtb-containing vacuoles (inset) in WT conditions (left panel), restricts generation of lipid droplets, an important nutrient reservoir of Mtb in host cells. Limited availability of host lipids confines intracellular replication of the pathogen and permits induction of adaptive immune responses. Absence of IRG1 during Mtb infection (right panel) leads to uncontrolled formation of lipid droplets and exacerbated pathogen growth in host cells. Increased inflammation in the lung and infiltration of neutrophils further allows Mtb dissemination and reduces numbers of recruited $B$ and $T$ lymphocytes, which possibly attenuates adaptive immunity. 


\section{Supplementary figures}

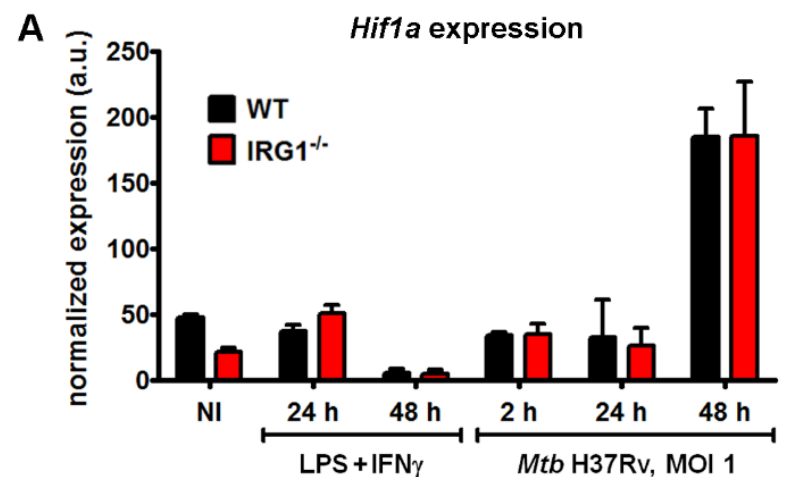

C

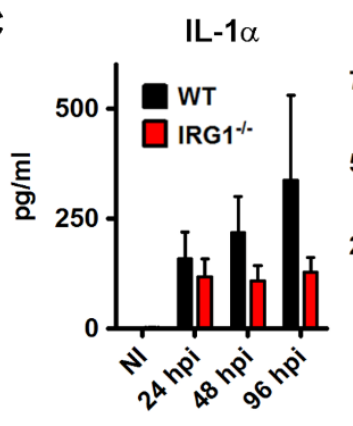

D

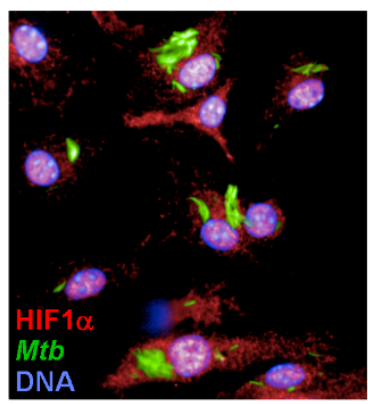

$$
\text { IL-1 } \beta
$$

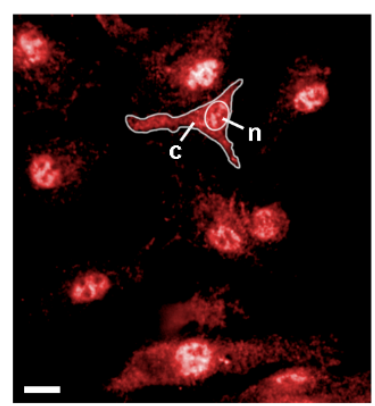

B

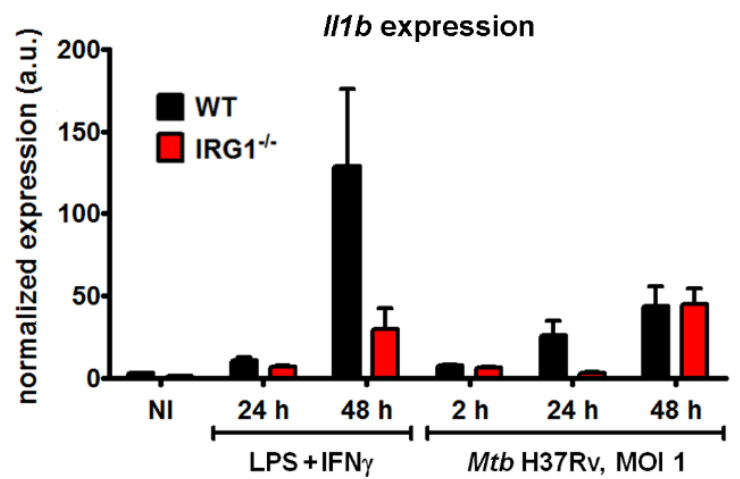

IL-6

MCP-1

TNF
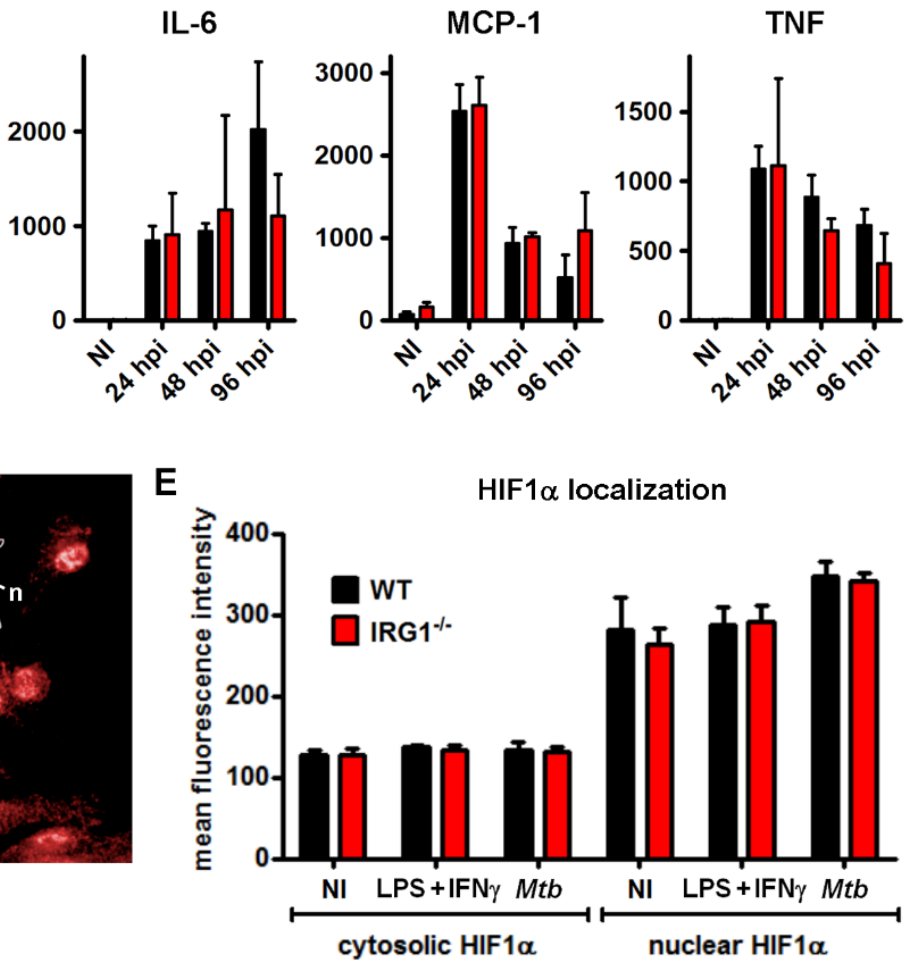

Figure S1. Comparative analysis of HIF1 $\alpha$ expression and secretion of inflammatory cytokines during Mtb infection. WT and IRG1\% BMDMs were either treated with $100 \mathrm{ng} / \mathrm{ml} \mathrm{LPS} \mathrm{and} 20 \mathrm{ng} / \mathrm{ml} \mathrm{IFN} \gamma$ or infected with $\mathrm{Mtb} \mathrm{H} 37 \mathrm{Rv}(\mathrm{MOI}=1)$ for the indicated time points. Non-infected $(\mathrm{NI})$ cells were used as controls. Expression of Hif1a (A) and $/ 11 \mathrm{~b}$ mRNA (B), normalized to the expression of Gapdh mRNA used as housekeeping gene, were determined by quantitative RT-PCR. C) Secretion of IL-1 $\alpha$, IL-1 $\beta$, IL-6, MCP1 (also known as CCL2) and TNF by BMDMs at the indicated dpi compared to NI controls. Cytokine concentration in the culture medium was measured by cytometric bead assay (CBA). D) Confocal microscopy image of the subcellular localization of HIF1 $\alpha$ (red), Mtb H37Rv-GFP (green) and nuclei (blue) in BMDMs at 24 hpi. Example of the applied mask to distinguish between cytosolic (c) and nuclear (n) 
localization of HIF1 $\alpha$ (right panel) by automated confocal microscopy. Bar: $10 \mu \mathrm{m}$. E) Histogram displaying the mean fluorescence intensity of cytosolic and nuclear HIF1 $\alpha$ levels between the different conditions determined by automated confocal microscopy and image analysis. Shown are mean \pm SEM of cells obtained from three individual mice per group in all experiments. 

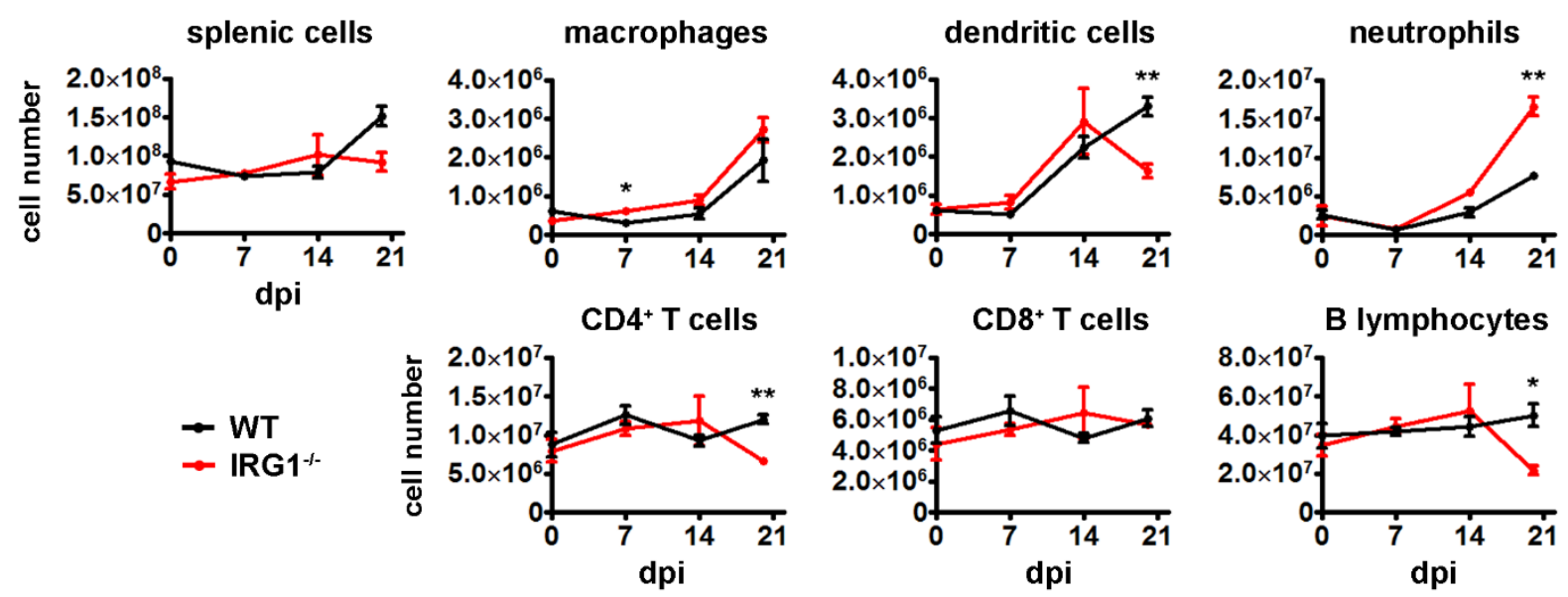

Figure S2. Comparative study of splenic cell populations in Mtb-infected WT and IRG1/- mice (related to Fig. 6). Histograms depicting changes of cell numbers of diverse immune cell populations in the spleen during the course of Mtb H37Rv infection, as determined by flow cytometry using specific cell surface markers. All cell numbers were normalized to the total cell number analyzed in each sample and were extrapolated to the whole organ. Shown are mean \pm SEM of cells obtained from three individual mice per group. * $P$ value $<0.05,{ }^{* *} P$ value $<0.01$, as determined by Mann-Whitney test. 


\section{Supplementary tables}

Table S1. Sequences of the RT-PCR primers used in this study (related to Fig. 1 and Fig. S1).

\begin{tabular}{lll}
\hline Gene & forward primer sequence & reverse primer sequence \\
\hline $\boldsymbol{l r g} \mathbf{1}$ & GGCACAGAAGTGTTCCATAAAGT & GAGGCAGGGCTTCCGATAG \\
$\boldsymbol{\boldsymbol { l l 1 } \mathbf { b }}$ & GCAACTGTTCCTGAACTCAACT & ATCTTTTGGGGTCCGTCAACT \\
\hline $\boldsymbol{H i f 1 a}$ & ACCTTCATCGGAAACTCCAAAG & CTGTTAGGCTGGGAAAAGTTAGG \\
\hline Gapd $\boldsymbol{n}$ & TGGCCTTCCGTCTCCCTAC & GAGTTGCTGTTGAAGTCGCA \\
\hline
\end{tabular}


Table S2. Applied in-house multi-parametric script used in Columbus (version 2.3.1, PerkinElmer) to determine Mtb replication (related to Fig. 2).

\begin{tabular}{|c|c|c|c|}
\hline Input Image & $\begin{array}{l}\text { Stack Processing: } \\
\text { Individual Planes } \\
\text { Flat field } \\
\text { Correction: None }\end{array}$ & Method & Output \\
\hline $\begin{array}{l}\text { Calculate } \\
\text { Image }\end{array}$ & & $\begin{array}{l}\text { Method : By Formula } \\
\text { Formula : iif(A>200,A,0) } \\
\text { Channel A : Exp1Cam1 } \\
\text { Negative Values : Set to Zero } \\
\text { Undefined Values : Set to Local } \\
\text { Average }\end{array}$ & $\begin{array}{l}\text { Output Image : } \\
\text { DAPImask }\end{array}$ \\
\hline Find Nuclei & $\begin{array}{l}\text { Channel : } \\
\text { DAPImask } \\
\text { ROI : None }\end{array}$ & $\begin{array}{l}\text { Method : B } \\
\text { Common Threshold : } \underline{0.8} \\
\text { Area : }>30 \mu \mathrm{m}^{2} \\
\text { Split Factor : } 7 \\
\text { Individual Threshold : } 0.4 \\
\text { Contrast : }>0.1\end{array}$ & $\begin{array}{l}\text { Output } \\
\text { Population : } \\
\text { Nuclei }\end{array}$ \\
\hline $\begin{array}{l}\text { Find } \\
\text { Cytoplasm }\end{array}$ & $\begin{array}{l}\text { Channel: } \\
\text { Exp1Cam1 } \\
\text { Nuclei : Nuclei }\end{array}$ & $\begin{array}{l}\text { Method : A } \\
\text { Individual Threshold : } \underline{0.3}\end{array}$ & \\
\hline $\begin{array}{l}\text { Select } \\
\text { Population }\end{array}$ & Population : Nuclei & $\begin{array}{l}\text { Method: Common Filters } \\
\text { Remove Border Objects } \\
\text { Region : Cell }\end{array}$ & $\begin{array}{l}\text { Output } \\
\text { Population : } \\
\text { Cells selected }\end{array}$ \\
\hline $\begin{array}{l}\text { Calculate } \\
\text { Image }\end{array}$ & & $\begin{array}{l}\text { Method : By Formula } \\
\text { Formula : iif(A>200, A, 0) } \\
\text { Channel A : Exp2Cam2 } \\
\text { Negative Values : Set to Zero } \\
\text { Undefined Values : Set to Local } \\
\text { Average }\end{array}$ & $\begin{array}{l}\text { Output Image : } \\
\text { Mtb Mask }\end{array}$ \\
\hline Find Spots & $\begin{array}{l}\text { Channel : Mtb } \\
\text { Mask } \\
\text { ROI : Cells } \\
\text { selected } \\
\end{array}$ & $\begin{array}{l}\text { Method : A } \\
\text { Relative Spot Intensity : >0.03 } \\
\text { Splitting Coefficient : } \underline{0.54} \\
\text { Calculate Spot Properties }\end{array}$ & $\begin{array}{l}\text { Output } \\
\text { Population : } \\
\text { Intracellular Mtb }\end{array}$ \\
\hline $\begin{array}{l}\text { Calculate } \\
\text { Morphology } \\
\text { Properties }\end{array}$ & $\begin{array}{l}\text { Population : } \\
\text { Intracellular Mtb } \\
\text { Region : Spot } \\
\end{array}$ & $\begin{array}{l}\text { Method : Standard } \\
\text { Area }\end{array}$ & $\begin{array}{l}\text { Output } \\
\text { Properties : } \\
\text { Intracellular Mtb }\end{array}$ \\
\hline $\begin{array}{l}\text { Calculate } \\
\text { Properties }\end{array}$ & $\begin{array}{l}\text { Population : Cells } \\
\text { selected }\end{array}$ & $\begin{array}{l}\text { Method : By Related Population } \\
\text { Related Population : Intracellular Mtb } \\
\text { Number of Intracellular Mtb } \\
\text { Intracellular Myb Area }\left[\mathrm{px}^{2}\right] \\
\end{array}$ & $\begin{array}{l}\text { Output } \\
\text { Properties : per } \\
\text { Cell }\end{array}$ \\
\hline $\begin{array}{l}\text { Select } \\
\text { Population }\end{array}$ & $\begin{array}{l}\text { Population : Cells } \\
\text { selected }\end{array}$ & $\begin{array}{l}\text { Method : Filter by Property } \\
\text { Number of Intracellular Mtb- per Cell : } \\
>0\end{array}$ & $\begin{array}{l}\text { Output } \\
\text { Population : } \\
\text { Infected cells }\end{array}$ \\
\hline Define Results & \multicolumn{3}{|c|}{$\begin{array}{l}\text { Method: List of Outputs } \\
\text { Number of Objects } \\
\text { Population : Intracellular Mtb } \\
\text { Intracellular Mtb Area [px²] : Sum } \\
\text { Population : Infected Cells } \\
\text { Intracellular Mtb Area [px²]- Sum per Cell : Mean } \\
\text { Method : Formula Output } \\
\text { Formula : a/b*100 }\end{array}$} \\
\hline
\end{tabular}


bioRxiv preprint doi: https://doi.org/10.1101/761551; this version posted September 8,2019 . The copyright holder for this preprint (which was not certified by peer review) is the author/funder. All rights reserved. No reuse allowed without permission.

Population Type : Objects

Variable A : Infected Cells - Number of Objects

Variable B : Cells Selected - Number of Objects

Output Name : \% Infected cells 
Table S3. Applied in-house multi-parametric script used in Columbus (version 2.3.1, PerkinElmer) to determine lipid droplet generation (related to Fig. 3).

\begin{tabular}{|c|c|c|c|}
\hline Input Image & $\begin{array}{l}\text { Stack } \\
\text { Processing: } \\
\text { Individual Planes } \\
\text { Flat field } \\
\text { Correction: } \\
\text { None }\end{array}$ & Method & Output \\
\hline $\begin{array}{l}\text { Calculate } \\
\text { Image }\end{array}$ & & $\begin{array}{l}\text { Method : By Formula } \\
\text { Formula : iif(A>150, A, 0) } \\
\text { Channel A : Exp1Cam1 } \\
\text { Negative Values : Set to Zero } \\
\text { Undefined Values : Set to Local } \\
\text { Average }\end{array}$ & $\begin{array}{l}\text { Output Image : } \\
\text { DAPI mask }\end{array}$ \\
\hline $\begin{array}{l}\text { Calculate } \\
\text { Image }\end{array}$ & & $\begin{array}{l}\text { Method : By Formula } \\
\text { Formula : iif(A>200,A,0) } \\
\text { Channel A : Exp2Cam2 } \\
\text { Negative Values : Set to Zero } \\
\text { Undefined Values : Set to Local } \\
\text { Average }\end{array}$ & $\begin{array}{l}\text { Output Image : Mtb } \\
\text { Mask }\end{array}$ \\
\hline $\begin{array}{l}\text { Calculate } \\
\text { Image }\end{array}$ & & $\begin{array}{l}\text { Method : By Formula } \\
\text { Formula : iif(A>350,A,0) } \\
\text { Channel A : Exp2Cam3 } \\
\text { Negative Values : Set to Zero } \\
\text { Undefined Values : Set to Local } \\
\text { Average }\end{array}$ & $\begin{array}{l}\text { Output Image : LD } \\
\text { Mask }\end{array}$ \\
\hline Find Nuclei & $\begin{array}{l}\text { Channel : DAPI } \\
\text { mask } \\
\text { ROI : None }\end{array}$ & $\begin{array}{l}\text { Method : B } \\
\text { Common Threshold : } \underline{0.4} \\
\text { Area : > } 20 \mu \mathrm{m}^{2} \\
\text { Split Factor }: 7 \\
\text { Individual Threshold : } \underline{0.4} \\
\text { Contrast : }>0.1\end{array}$ & $\begin{array}{l}\text { Output Population : } \\
\text { Nuclei }\end{array}$ \\
\hline $\begin{array}{l}\text { Find } \\
\text { Cytoplasm }\end{array}$ & $\begin{array}{l}\text { Channel: } \\
\text { Exp2Cam3 } \\
\text { Nuclei : Nuclei }\end{array}$ & $\begin{array}{l}\text { Method: B } \\
\text { Common Threshold : } \underline{0.2} \\
\text { Individual Threshold }: \underline{0.2}\end{array}$ & \\
\hline Find Spots & $\begin{array}{l}\text { Channel : Mtb } \\
\text { Mask } \\
\text { ROI : Nuclei }\end{array}$ & $\begin{array}{l}\text { Method : B } \\
\text { Detection Sensitivity : } 0.5 \\
\text { Splitting Coefficient : } 0.5 \\
\text { Calculate Spot Properties } \\
\end{array}$ & $\begin{array}{l}\text { Output Population: } \\
\text { Mtb }\end{array}$ \\
\hline $\begin{array}{l}\text { Calculate } \\
\text { Properties }\end{array}$ & $\begin{array}{l}\text { Population: } \\
\text { Nuclei }\end{array}$ & $\begin{array}{l}\text { Method : By Related Population } \\
\text { Related Population : Mtb } \\
\text { Number of Mtb } \\
\text { Spot Area }\left[\mathrm{px}^{2}\right]\end{array}$ & $\begin{array}{l}\text { Output Properties: } \\
\text { per Cell }\end{array}$ \\
\hline $\begin{array}{l}\text { Find } \\
\text { Micronuclei }\end{array}$ & $\begin{array}{l}\text { Channel : } \\
\text { Exp2Cam3 } \\
\text { Population : } \\
\text { Nuclei } \\
\text { Cell Region : } \\
\text { Cell }\end{array}$ & $\begin{array}{l}\text { Method : A } \\
\text { Micronucleus to Cytoplasm Intensity : } \\
>0.15 \\
\text { Calculate Micronuclei Properties } \\
\text { Unit for Properties : px }\end{array}$ & $\begin{array}{l}\text { Output Population : } \\
\text { LD candidates }\end{array}$ \\
\hline $\begin{array}{l}\text { Calculate } \\
\text { Morphology } \\
\text { Properties } \\
\end{array}$ & $\begin{array}{l}\text { Population : LD } \\
\text { candidates }\end{array}$ & $\begin{array}{l}\text { Method : Standard } \\
\text { Area } \\
\text { Roundness }\end{array}$ & $\begin{array}{l}\text { Output Population : } \\
\text { LD candidate }\end{array}$ \\
\hline
\end{tabular}




\begin{tabular}{|c|c|c|c|}
\hline & \multicolumn{3}{|l|}{$\begin{array}{l}\text { Region : } \\
\text { Micronucleus }\end{array}$} \\
\hline $\begin{array}{l}\text { Select } \\
\text { Population }\end{array}$ & Population : LD & $\begin{array}{l}\text { Method : Filter by Property } \\
\text { Spot to Region Intensity : >= } 1 \\
\text { Spot Contrast : }>0.1 \\
\text { Boolean Operations : F1 and F2 }\end{array}$ & $\begin{array}{l}\text { Output Population : } \\
\text { LD candidates }\end{array}$ \\
\hline $\begin{array}{l}\text { Select } \\
\text { Population }\end{array}$ & $\begin{array}{l}\text { Population : LD } \\
\text { candidates }\end{array}$ & $\begin{array}{l}\text { Method : Filter by Property } \\
\text { LD candidates Area }\left[\mathrm{px}^{2}\right]:<=\underline{45}\end{array}$ & $\begin{array}{l}\text { Output } \\
\text { Population : : LD } \\
\text { selected }\end{array}$ \\
\hline $\begin{array}{l}\text { Calculate } \\
\text { Intensity } \\
\text { Properties }\end{array}$ & $\begin{array}{l}\text { Channel : } \\
\text { Exp2Cam3 } \\
\text { Population : LD } \\
\text { Selected } \\
\text { Region : } \\
\text { Micronucleus }\end{array}$ & $\begin{array}{l}\text { Method : Standard } \\
\text { Mean } \\
\text { Maximum }\end{array}$ & $\begin{array}{l}\text { Output Population : } \\
\text { Intensity LD } \\
\text { Selected } \\
\text { Exp2Cam3 }\end{array}$ \\
\hline $\begin{array}{l}\text { Calculate } \\
\text { Properties }\end{array}$ & $\begin{array}{l}\text { Population : } \\
\text { Nuclei }\end{array}$ & $\begin{array}{l}\text { Method : By Related Population } \\
\text { Related Population : LD Selected } \\
\text { Number of LD Selected } \\
\text { LD candidates Area [px²] } \\
\text { Intensity LDselected Exp2Cam3 } \\
\text { Mean } \\
\text { Intensity LDselected Exp2Cam3 } \\
\text { Maximum }\end{array}$ & $\begin{array}{l}\text { Output Properties: } \\
\text { per Cell }\end{array}$ \\
\hline $\begin{array}{l}\text { Select } \\
\text { Population }\end{array}$ & $\begin{array}{l}\text { Population : } \\
\text { Nuclei }\end{array}$ & $\begin{array}{l}\text { Method : Filter by Property } \\
\text { Number of Mtb- per Cell : >= } 1\end{array}$ & $\begin{array}{l}\text { Output Population : } \\
\text { IFC }\end{array}$ \\
\hline $\begin{array}{l}\text { Select } \\
\text { Population }\end{array}$ & $\begin{array}{l}\text { Population: } \\
\text { Nuclei }\end{array}$ & $\begin{array}{l}\text { Method : Filter by Property } \\
\text { Number of Mtb- per Cell : }==0\end{array}$ & $\begin{array}{l}\text { Output Population : } \\
\text { Non-IFC }\end{array}$ \\
\hline $\begin{array}{l}\text { Select } \\
\text { Population }\end{array}$ & Population : IFC & $\begin{array}{l}\text { Method : Filter by Property } \\
\text { Number of LD Selected- per Cell : >= } \\
1\end{array}$ & $\begin{array}{l}\text { Output Population : } \\
\text { LDPosIFC }\end{array}$ \\
\hline $\begin{array}{l}\text { Select } \\
\text { Population }\end{array}$ & $\begin{array}{l}\text { Population : Non- } \\
\text { IFC }\end{array}$ & $\begin{array}{l}\text { Method : Filter by Property } \\
\text { Number of LD Selected- per Cell : >= } \\
1\end{array}$ & $\begin{array}{l}\text { Output Population : } \\
\text { LDPosNon-IFC }\end{array}$ \\
\hline Define Results & $\begin{array}{l}\text { Method: List of Ol } \\
\text { Population : Mtb } \\
\text { Spot Area [px²] : S } \\
\text { Population : LD Se } \\
\text { Intensity LDselecte } \\
\text { Intensity LDselecte } \\
\text { Population : LDPo } \\
\text { Number of LD Sele } \\
\text { LD candidates Are } \\
\text { Intensity LDselecte } \\
\text { Intensity LDselecte } \\
\text { Population : LDPc } \\
\text { Number of LD Sel } \\
\text { LD candidates Are } \\
\text { Intensity LDselecte } \\
\text { Intensity LDselecte } \\
\\
\text { Method : Formula } \\
\text { Formula : a/b¹00 } \\
\text { Population Type : }\end{array}$ & 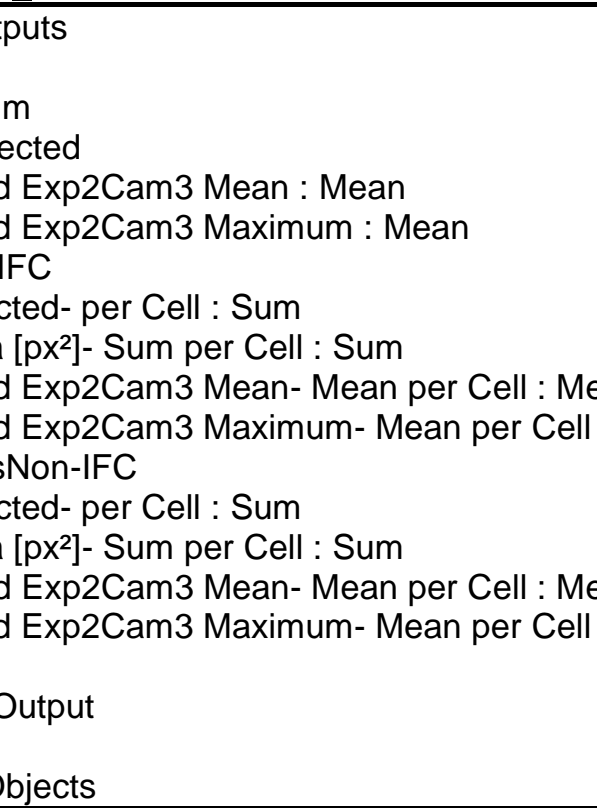 & $\begin{array}{l} \\
\text { Mean } \\
\text { Mean } \\
\text { In }\end{array}$ \\
\hline
\end{tabular}


Variable A : IFC - Number of Objects

Variable B : Nuclei - Number of Objects

Output Name : \% Infected cell

Method : Formula Output

Formula : $a / b^{*} 100$

Population Type : Objects

Variable A : LDPosIFC - Number of Objects

Variable B : IFC - Number of Objects

Output Name : \% LDPosIFC

Method : Formula Output

Formula : $a / b^{*} 100$

Population Type : Objects

Variable A : LDPosNon-IFC - Number of Objects

Variable B : Non-IFC - Number of Objects

Output Name : \% LDPosNon-IFC

Method : Formula Output

Formula : $a / b$

Population Type : Objects

Variable A : IFC - Number of LD Selected- per Cell Sum

Variable B : IFC - Number of Objects

Output Name : LD number/IFC

Method : Formula Output

Formula : $a / b$

Population Type : Objects

Variable A : NonIFC - Number of LD Selected- per Cell Sum

Variable B : NonIFC - Number of Objects

Output Name : LD number/NonIFC

Method : Formula Output

Formula : a/b

Population Type : Objects

Variable A : IFC - Number of LD Selected- per Cell Sum

Variable B : LDposIFC - Number of Objects

Output Name : LD number/LDposIFC

Method : Formula Output

Formula : $a / b$

Population Type : Objects

Variable A : NonIFC - Number of LD Selected- per Cell Sum

Variable B : LDposNonIFC - Number of Objects

Output Name : LD number/LDposNonIFC 